NBER WORKING PAPER SERIES

\title{
FEMALE EARNINGS INEQUALITY: \\ THE CHANGING ROLE OF FAMILY CHARACTERISTICS ON \\ THE EXTENSIVE AND INTENSIVE MARGINS
}

\author{
David Card \\ Dean R. Hyslop \\ Working Paper 25387 \\ http://www.nber.org/papers/w25387 \\ NATIONAL BUREAU OF ECONOMIC RESEARCH \\ 1050 Massachusetts Avenue \\ Cambridge, MA 02138 \\ December 2018
}

This research was supported in part by the Royal Society of New Zealand Marsden Fund Grant MEP1301. We thank Janet Currie for very useful comments on an earlier draft. We also thank Dave Mare for many helpful discussions and Thomas Xiao for excellent research assistance. The views expressed herein are those of the authors and do not necessarily reflect the views of the National Bureau of Economic Research.

NBER working papers are circulated for discussion and comment purposes. They have not been peer-reviewed or been subject to the review by the NBER Board of Directors that accompanies official NBER publications.

(C) 2018 by David Card and Dean R. Hyslop. All rights reserved. Short sections of text, not to exceed two paragraphs, may be quoted without explicit permission provided that full credit, including (c) notice, is given to the source. 
Female Earnings Inequality: The Changing Role of Family Characteristics on the Extensive and Intensive Margins

David Card and Dean R. Hyslop

NBER Working Paper No. 25387

December 2018

JEL No. J22

\begin{abstract}
Although women make up nearly half the U.S. workforce, most studies of earnings inequality focus on men. This is at least in part because of the complexity of modeling both the decision to work (i.e., the extensive margin) and the level of earnings conditional on work (the intensive margin). In this paper we document a series of descriptive facts about female earnings inequality using data for three cohorts in the PSID. We show that inequality in annual earnings of women fell sharply between the late 1960s and the mid-1990s, with a particularly large decline in the extensive margin component. We then fit earnings-generating models that incorporate both intensive- and extensive-margin dynamics to data for the three cohorts. Our models suggest that over $80 \%$ of the decline in female earnings inequality can be attributed to a weakening of the link between family-based factors (including the number of children of different ages and the presence and incomes of partners) and the intensive and extensive margins of earnings determination.
\end{abstract}

\author{
David Card \\ Department of Economics \\ 549 Evans Hall, \#3880 \\ University of California, Berkeley \\ Berkeley, CA 94720-3880 \\ and NBER \\ card@econ.berkeley.edu \\ Dean R. Hyslop \\ Motu Economic and Public Policy Research Trust \\ PO Box 24390 \\ Wellington 6142 \\ New Zealand \\ dean.hyslop@motu.org.nz
}




\section{Introduction}

In contrast to the vast literature on the rise in earnings inequality among U.S. men (e.g., Katz and Autor, 1999;Haider, 2001; DeBacker et al., 2013), far less is known about the patterns for women. Figure 1 shows a simple measure of inequality the standard deviation of log annual earnings for those with positive earnings - for male and female workers age $24-60$ over the period from 1968 to $2014 .^{1}$ While male earnings inequality has risen over the past 50 years, female earnings inequality has fallen, and is now only slightly higher than the level among working men.

The difference in trends in Figure 1 raises a number of questions. An important initial question is whether the same relative trends are evident when the measure of inequality is broadened to include both workers and non-workers. Although female employment rates have risen substantially since the 1960s, they remain lower and more intermittent than those of men. Thus, it is important to consider measures of inequality that incorporate both the extensive and intensive margins of variation in earnings among women. ${ }^{2}$ A second and related question is whether the trends in inequality for women and the changes in the intensive and extensive margin components can be described by a simple behavioral model that incorporates both the decision to work in a given year (as in Heckman, 1978 and Hyslop, 1999) and earnings conditional on work (as in MaCurdy, 1982; Abowd and Card, 1989;

\footnotetext{
${ }^{1}$ These data are drawn from the March Current Population Survey (CPS). For consistency with the earnings concept in our PSID samples we sum labor earnings, self-employment earnings, and farm earnings, though the results are quite similar if we only focus on labor earnings. We have censored (Winsorized) earnings for those with positive reported values at the 5th and 99th percentiles of the distributions in each year for each gender. We do not exclude allocated earnings or make any attempt to deal with topcoding: we note that top-coding probably leads to some understatement in the rise in inequality for males (e.g., Katz and Autor, 1999).

${ }^{2}$ An alternative approach is to focus on earnings for those who work, but adjust for changing selectivity of the group with positive earnings. This is the approach adopted by Mulligan and Rubinstein (2008), for example, in studying changes in the level of female wages.
} 
Meghir and Pistaferri, 2004 and Guvenen, 2007). Assuming that is the case, it is then interesting quantify the impacts of different factors - including family-related factors such as the presence of children and partners - in explaining the changes in earnings inequality among women.

In this paper we address these questions using data on three consecutive cohorts of women drawn from the Panel Study of Income Dynamics (PSID). Specifically, we study working age women who are observed in 10-year panels covering the intervals 1968-77, 1978-87, and 1988-97. Consistent with trends for the female population as a whole, the average employment rate in our PSID samples rose from $55 \%$ in 1968 to just under $80 \%$ in 1997 . Thus our samples capture an important share of the remarkable rise in female employment that occurred in the second half of the 20th century (see e.g., Goldin, 1990).

We begin with a descriptive analysis of the relative contributions of the extensive and intensive margins to the total variation in individuals' annual earnings. We develop a simple decomposition of the squared coefficient of variation $\left(C V^{2}\right)$ of earnings in a panel setting that partitions overall inequality into within-person components, between-person components, and an interaction term (which in our case is small). We then show how the within- and between-person components can be decomposed into intensive-margin and extensive-margin components. Much of the existing literature on earnings dynamics focuses on the within-person/intensive-margin component. For individuals who always work this is (approximately) the within-person variance of earnings, and is closely related to measures of the "transitory" component of earnings in the earnings volatility literature (Gottschalk and Moffitt, 1994; Shin and Solon, 2011). The complementary extensive-margin component of within-person inequality depends on an 
individual's average probability of employment, and is zero for those who always work. Finally, the intensive- and extensive-margin components of between-person inequality depend on the variance of average earnings when employed and the average employment rate, respectively. In a population that always works, the former is just the variance in "permanent" earnings, defined as the individual-specific mean of earnings over all years in the panel.

Applying this framework to the three cohorts of women from the PSID we reach three main conclusions. First, consistent with the trend documented in Figure 1, we find that overall inequality in female earnings has declined remarkably, with a 50\% decline in $C V^{2}$ between the early cohort (observed 1968-77) and the late cohort (observed 1988-97). Second, this fall is attributable to declines in both the within-person and between-person components. Indeed, the relative shares of these components have remained quite stable, with the between-person share remaining at about $80 \%$. Third, a relatively large share of the decline in betweenperson inequality is attributable to reductions in the extensive-margin component, reflecting the rise in the average probability of employment for women in the third cohort relative to the first.

In contrast to these trends among women, we show that earnings inequality $\boldsymbol{i n}$ creased significantly for men in the same three cohorts, with most of the increase attributable to rises in the intensive-margin components. Consistent with Haider (2001), we find that the relative share of the within-person/intensive margin component of inequality - which corresponds to the "transitory" earnings component in his analysis - was roughly constant. ${ }^{3}$

\footnotetext{
${ }^{3}$ Celik et al. (2012) show that trends in the purely transitory component of earnings inequality for males are somewhat different in the PSID than in other data sets, including the Survey of Income and Program Participation (SIPP) and administrative earnings records.
} 
Following this descriptive analysis, we then develop a statistical earnings generating function (EGF) that jointly summarizes the extensive and intensive margins of earnings variation. Our approach combines a standard specification for the evolution of individuals' latent earnings (Abowd and Card, 1989; MaCurdy, 1982; Meghir and Pistaferri, 2011), with a dynamic discrete choice model of employment (Heckman, 1978; Hyslop, 1999), allowing a fairly general correlation structure between the underlying error components in the two models. ${ }^{4}$ We fit the model separately by cohort to the observed participation and earnings data for each woman in the sample, taking as given the number and ages of her co-resident children and her marriage/partnership status in each year. ${ }^{5}$ We show that this model captures the main features of the earnings data for women in all three cohorts through a combination of observed factors (including family-based factors) and unobserved error components that capture both permanent and transitory shocks to latent earnings.

A feature of our approach is that we can flexibly model the channels through which the observable factors affect the choice of whether to work or not in a given year and earnings conditional on work. Building on a standard correlated random effects specification we include the average characteristics of a person's family, such as the fraction of years she has children under age 5 at home, the fraction of years she has a partner, and the average earnings of her spouse/partner, as

\footnotetext{
${ }^{4}$ We do not attempt to separately model hours and wages for those who work. Altonji et al. (2013) estimate a dynamic model of hours and employment with a simplified specification of behavioral responses to current wage opportunities. They find that the behavioural responses are quite small on both the intensive and extensive margins. This suggests it may be relatively costless to ignore these responses and focus on the extensive (employment) and intensive (wages and hours) margins of earnings.

${ }^{5}$ We do not attempt to model fertility, or the co-residency decisions of older children, or a woman's partnership status, though these would be interesting extensions of our approach.
} 
well as the corresponding period-specific variables (whether she has any children under age 5 in the current year, whether she has a partner in the current year, and the deviation of her partner's income from its long-term average). This allows us to separate the selection effects associated with average differences in the family variables from the current year effects.

Using our models to simulate the effects of the family-related variables in each cohort, we show that a key factor in the decline of earnings inequality between our three cohorts is the systematic weakening of family-related forces. In our earliest cohort of women, child- and partner-related variables explain over half of overall inequality in earnings, reflecting the powerful impact of family circumstances on the labor supply choices of women born prior to World War II. These variables matter far less for women in our latest cohort, accounting for only about one-fifth of earnings inequality. Comparing across cohorts we conclude that the diminishing effect of family-related variables accounts for over $80 \%$ of the overall decline in female earnings inequality.

Our work draws together and contributes to three separate strands of literature. First, we contribute to the literature that analyzes the factors behind the rise in female employment over recent decades (e.g., Juhn and Murphy, 1997; Blau and Kahn, 2007). We generalize the standard specifications in that literature - which use repeated cross sectional data - by incorporating both current period characteristics and average family characteristics. This allows us to compare the direct impacts of family-related variables in the current year with the selection effects associated with different average family circumstances. Second, we contribute to the literature on earnings dynamics (e.g., MaCurdy, 1982; Abowd and Card, 1989; Baker and Solon, 2003; Meghir and Pistaferri, 2004; Guvenen, 2007) which has 
mainly focused on the earnings of continuously employed men. Specifically, we extend the standard permanent-transitory specification of the dynamic behavior of earnings conditional on work to incorporate periods of zero earnings. Third, we contribute to the earnings inequality literature (e.g., Haider, 2001; Kopczuk et al., 2010) by offering an analysis of female earnings inequality that incorporates non workers, and by separately identifying the contributions of the extensive and intensive margins to the overall variation in earnings.

In the next section of the paper we briefly summarizing the broad trends in female earnings inequality over the past 50 years, using data from the Current Population Survey (CPS) and the PSID. We then develop a simple framework for decomposing the components of variation in earnings, and apply this to the three cohorts of women from the PSID. With this background we then specify our earnings generating model, present the estimation results, and summarize the model's ability to describe earnings outcomes. In the final section we use the model to ask how the changing role of family-related factors has led to changes in the overall variation in female earnings, and the various components of this variation.

\section{Setting and Descriptive Overview}

\subsection{Trends in female earnings inequality}

We begin by summarizing the main trends in female employment and earnings since the late 1960s, using data from the March CPS for women age 24-60. ${ }^{6}$ Fig-

\footnotetext{
${ }^{6}$ Note that age is measured at the time of the CPS survey (usually in March) while earnings are reported for the previous calendar year. For simplicity we use the year of the survey as our index of time. We censor (Winsorize) total reported earnings each year at the 5th and 99th percentiles. We do not exclude observations with allocated earnings or attempt to address the
} 
ure 2 shows real mean earnings (including non workers with 0 earnings) and conditional real mean earnings (excluding the 0's), as well as the fraction who received positive earnings in the year. ${ }^{7}$ The figure confirms two well-known facts. First, real earnings of women in the U.S. have risen substantially over the past 5 decades. Second, part of the upward trend until year 2000 was a rising probability of work. Over the 20 years from 1968 to 1988 the growth in employment rates was particularly impressive, averaging about 1 percentage point per year. Thereafter the trend stalled, with a notable decline from the peak rate of around $78 \%$ in 2000 to $73 \%$ in the 2014 survey.

Next, in Figure 3, we plot three measures of earnings inequality: (1) the conditional coefficient of variation, $C V^{c}$, formed by dividing the standard deviation of annual earnings for those who work by the conditional mean earnings; (2) the standard deviation of $\log$ (annual earnings) for those with positive earnings, as in Figure 1; and (3) the coefficient of variation of annual earnings for all women, including those with zero earnings, $C V$. For reference we also show the employment rate. As noted in the introduction, the standard deviation of $\log$ (earnings) among female workers has gradually trended down during our sample period, from a value of 1.1 in the 1968 survey to about 0.85 in the 2014 survey. In contrast, $C V^{c}$ has trended upward relatively steadily from a value of about 0.75 in 1968 to 0.83 in $2014 .^{8}$ Most remarkably, the overall coefficient of variation $C V$ has fallen top-coding of earnings in the CPS. Finally, we present unweighted statistics throughout this paper, though these are not very different from weighted statististics using the weights provided for the March CPS earnings supplements.

${ }^{7}$ We deflate nominal earnings using the CPI to 2013 dollars.

${ }^{8} \mathrm{~A}$ common simplifying assumption is that earnings for those who work are log-normally distributed. Under that assumption, $C V^{c}=\left(\exp \left(\sigma^{2}\right)-1\right)^{1 / 2}$ where $\sigma$ is the standard deviation of log earnings. The differing trends in $C V^{c}$ and the standard deviation of log earnings suggest that the log-normality assumption is inappropriate for female annual earnings. This has implications for our modeling strategy later. 
substantially. The downward trend was particularly strong from the late 1960s to the early 1990s, coincident with the era of rising employment rates. ${ }^{9}$

A salient feature of all four series shown in Figure 3 is that most of the changes over the past 5 decades occurred during the 30 year period from the late 1960s to the late 1990s. Fortunately, this coincides with the period during which the PSID collected annual information on households and individuals. To take advantage of the rich information in the PSID without building a complex model that can accommodate the switch to a biennial interview schedule after 1997, we therefore limit our attention in the remainder of the paper to this three-decade period.

\section{$2.2 \quad$ PSID Samples}

From 1968 to 1997 the PSID conducted an annual survey of 5,000 or so families in the first half of the year that inquired about income and work during the previous calendar year (similar to the Annual Demographic Supplement to the March CPS). In selecting samples from the PSID for our analysis, we include individuals from both the nationally representative subsample of the PSID and the poverty subsample drawn from the Survey of Economic Opportunity (SEO), which made up about one-third of the original PSID families. As we discuss below, the trends in inequality are broadly similar whether we include the SEO subsample or not. To maintain larger sample sizes we therefore retain the SEO group. ${ }^{10}$

We have drawn separate panel samples of females and males from the annual survey over three non-overlapping 10-year periods (1968-77, 1978-87, and 198897). We require sample members to be between the ages of 24 and 60 in every year

\footnotetext{
${ }^{9}$ The simple correlation between $C V$ and the employment rate is -0.98 .

${ }^{10}$ We have excluded the Latino sample, which was part of the PSID from 1990 until 1995, because as discussed below we require individuals to be interviewed for 10 consecutive years.
} 
of the panel: thus each panel is (broadly) representative of "working age" adults during the particular years of the panel. Our female samples consists of women who responded to the PSID survey for 10 consecutive years and were either "heads" (of a single-headed family) or "wives" (married or unmarried female heads of dualheaded families) in each year. ${ }^{11}$ We emphasize that we do not require a woman to have the same partnership status from year to year: only that she be recorded as either a head or wife in each year. Similarly, our male samples consist of men who responded to the survey for 10 consecutive years and were a "head" of a single-headed or dual headed family in every year.

Table 1 presents summary statistics on the demographic characteristics and labor market outcomes of females in each of our three panels. We have between 2,000 and 2,500 individuals in each panel, yielding 20,000-25,000 person-year observations per panel. The modest number of individuals in each panel reflects the limited size of the original PSID sample, our fairly tight age restrictions, and sample attrition from the PSID. ${ }^{12}$ The average age of the women is about 40 in each panel; average education is about 11 years for the first panel, rising to just over 13 years for the third panel.

One unusual feature of our samples is the high fraction of African Americans ( $37 \%$ in the first panel, falling to $31 \%$ in the third). ${ }^{13}$ This is due to our inclusion of the SEO subsample. For reference, in Appendix Table 1 we show a parallel set of summary statistics for samples that exclude the SEO subsample. This restricted

\footnotetext{
${ }^{11}$ The PSID defines the "head" to be the male in a dual-headed family, and the "wife" to be the female. This terminology is both anachronistic and confusing, because "wives" do not have to be married to their male partner.

${ }^{12}$ See Fitzgerald et al. (1998) for an analysis of attrition in the PSID.

${ }^{13}$ The absence of Hispanic and Asian women reflects the demographic composition of the U.S. at the time the PSID was created.
} 
sample has a very similar age structure to our main sample, and somewhat higher mean education, but has only 8-9\% African Americans.

Another striking feature of our PSID samples is the relative stability in the fraction of women with a partner present (71\% in the first two panels, rising slightly to $74 \%$ in the third). This contrasts with the roughly 20 percentage point decline in the fraction of adult women in the U.S. who are married with a spouse present over our sample period (e.g. Stevenson and Wolfers, 2007). The discrepancy in trends between the PSID and national samples is present even when we drop the SEO sample. As shown in Appendix Table 1, the average fraction with a partner is around $84 \%$ in the first cohort when we exclude the SEO, falling only slightly to $81 \%$ in the third cohort. ${ }^{14}$ Nevertheless, within each of our PSID panels the trend in partnership rates closely parallels the general trend in marriage rates for women of the same ages in the same years. In Appendix Figure 1 we show the mean fraction of women with a partner for each calendar year in our PSID samples, along with the fraction of women who are married with spouse present in a March CPS sample with the same age restrictions. Although the average levels of partnership/marriage are different in the PSID and CPS samples, in both data sources we see a fairly steep fall in rates in the 1968-77 period, a smaller fall-off in the 1978-87 panel, and near stability in the 1988-97 panel.

In contrast to the relative stability in partnership rates across the three cohort samples, there is a notable decline in the fraction of women with a co-resident child. For example, in the 1968-77 cohort, $75 \%$ of women have a co-resident child

\footnotetext{
${ }^{14}$ The discrepancy appears to be due to a combination of our panel requirements, which causes us to drop women who attrit from the PSID, and features of the PSID sample. Fitzgerald et al. (1998) show that the fraction of males with a partner present in the PSID in 1989 is about 10 percentage points higher than in the CPS. They also show attrition rates are higher for non-married sample members and those with more marital transitions.
} 
in any year and 59\% always have at least one child at home. In the 1988-97 cohort these rates are $68 \%$ and $50 \%$, respectively. There is greater stability in the fraction with a child under 6 at home (27-29\% across all three cohorts). In Appendix Figure 2 we compare the fractions of women with a child under 6 at home in our PSID samples to rates for women of the same ages in the March CPS. We find a somewhat higher rate in our PSID samples, but the gap between the PSID and CPS samples is relatively stable across cohorts, and the trends within each cohort are also similar.

The middle panel of Table 1 shows a variety of statistics on employment and earnings for women in our samples. The average fraction of women working in any year rises from $58 \%$ in the earliest cohort to $80 \%$ in the latest cohort. ${ }^{15}$ The fraction of women who work in all years rises by even more, from $29 \%$ to $55 \%$, while the fraction who never work falls from $15 \%$ to $5 \%$. Not surprisingly, these changes were accompanied by shifts in the year-to-year transition probabilities between work and non work. For example, the fraction of women who were observed working in a given year following 2 prior years of non work rises from $13 \%$ to $17 \%$ between the first and third cohorts, while the fraction who are observed working after 2 prior years of work rises from $92 \%$ to $95 \%$.

The PSID reports annual labor earnings for heads and wives, which includes wages and salaries, farm income, and self-employment income. In order to reduce the impacts of outliers, we have censored (Winsorized) the reported data at the 5th and 99th percentiles in each year. Average annual earnings (measured in 2013 dollars) more than doubles from $\$ 11,400$ in our first panel to $\$ 25,600$ in our third

\footnotetext{
${ }^{15}$ We define a person to be working if they report positive labor earnings over the (previous) calendar year, and also positive hours of work over the year. We reset earnings to 0 for individuals with 0 hours but positive earnings.
} 
panel. This rise is driven by combination of an increase in average employment rates, an increase in hours conditional on working (from about 1,380 hours per year for the first panel to 1,660 hours per year for the third panel), and a rise in real hourly wages (from an average of $\$ 14.40$ per hour for the first panel to $\$ 20.30$ for the third). As shown in Appendix Table 1, the levels of average annual earnings are higher in each panel but the rise across panels is similar when we exclude the SEO sample.

The bottom panel of Table 1 shows some mean characteristics of spouses/partners for the 70-74 percent of women who have a partner at the time of the survey. On average the partners are in their early 40's, have about a $95 \%$ employment rate, and work about 2,200 hours per year if they are employed. Partners' annual earnings rise from an average of about $\$ 53,200$ to $\$ 65,100$ between the first and third panels, reflecting a roughly $20 \%$ rise in real hourly wages. Excluding the SEO sample, average partner earnings are higher in each panel but rise more slowly between panels. However, the fraction of spouses/partners who work in a given year is about the same whether the SEO sample is included or excluded.

Table 1 also shows mean characteristics of the women who are employed or not employed in a given year. As would be expected, working women have higher education than non workers, with a slightly larger gap in the third cohort than the first. In the 1968-77 panel, working women are less likely to have a partner present (66\% versus $78 \%)$ and less likely to have any children at home (71\% versus 81\%). In the 1988-97 panel these gaps are much smaller, reflecting a fall in the impacts of partner status and the presence of children in determining employment status. Interestingly, among women with a partner present there are relatively few differences in partners' employment rates or hours between women who work and 
those who do not.

\subsection{Comparisons of PSID Samples with CPS}

Given the small and somewhat unrepresentative nature of our PSID panels, an important question is whether the trends in earnings outcomes within and between the three panels broadly match the trends for the overall population of females in the U.S. Figures 4a-4d overlay estimates of four key earnings outcomes based on annual observations from each of our panels against the corresponding estimates derived from the CPS. Specifically, we examine the average employment rate, mean earnings conditional on work, the unconditional $C V$ of earnings, and the standard deviation of log earnings. Our reading of these figures is that the trends in employment, earnings, and the dispersion in earnings are broadly similar across the two data sources, with our PSID panels capturing the three main features that are apparent in the national CPS samples, including a rising employment rate, a falling coefficient of variation of overall earnings, and a relatively flat standard deviation of earnings conditional on working.

One interesting feature of the PSID samples is that we can potentially isolate the component of the trend in female labor market outcomes that is due to differences between cohorts. Looking at Figure 4a, for example, it appears that the year-to-year growth in employment rates within a panel is slower than the economy-wide growth rate, and that there are large jumps between the 3 panels. In fact, about 15 percentage points of the overall 20 percentage point increase in average female employment rates from 1968 to 1997 occurs at the between-cohort jumps. Similarly, 0.26 of the roughly 0.40 decline in the $C V$ of unconditional 
earnings over the sample period occurs at the between-cohort jumps.

\subsection{Volatility of Earnings}

While our primary focus in this paper is on understanding overall earnings inequality and the changing contributions of intensive- and extensive-margin components, an important strand of recent research focuses more narrowly on the variability of within-person changes in earnings. This literature originated with Gottschalk and Moffitt (1994), who argued that the variance of the transitory component of male earnings in the PSID had increased in the 1980s, potentially accounting for an important share of the overall rise in male earnings inequality. Shin and Solon (2007) noted that this variance component is closely related to the cross-sectional variance of individual earnings changes, which can be calculated using rolling 2-year panels. Many subsequent papers (e.g., Sabelhaus and Song, 2010; DeBacker et al., 2013) have used a variety of different data sources and samples to construct three main measures of earnings changes: (1) the standard deviation of the "arc-percentage" change in earnings between consecutive years; ${ }^{16}$ (2) the standard deviation of the arc-percentage change in earnings for those who work in both years; and (3) the standard deviation of the change in log earnings for those who work in both years.

Figure 5 shows all three of these measures for our PSID samples. Consistent with the findings in recent studies that report data for female workers (e.g., Dahl et al., 2011, Figure A-2; Ziliak et al., 2011; Celik et al., 2012) we see a decline in the variability of earnings changes for those who are observed with positive

\footnotetext{
${ }^{16}$ Letting $y_{i t}$ denote earnings of a given person $i$ in year $t$, the arc-percent change is: $2\left(y_{i t}-\right.$ $\left.y_{i t-1}\right)\left(y_{i t}+y_{i t-1}\right)$. The variance of this is numerically equal to the mean squared coefficient of variation of within-person earnings changes - see below.
} 
earnings in consecutive years. As we discuss below, these measures of volatility are closely related to the within-person component of variation that arises from our broader decomposition. The downward trends in year-to-year volatility shown in Figure 5 are consistent with decreases in the within-person components of earnings inequality discussed below.

\section{Quantifying the components of earnings in- equality}

In this section we present a simple statistical framework for quantifying the components of earnings inequality in a panel data setting with both intensive and extensive margin variation. In order to handle zero earnings associated with periods of non-employment, we use the squared coefficient of variation of earnings $\left(C V^{2}\right)$ as our summary measure of inequality. In the absence of observations with zero earnings, $C V^{2}$ provides a first-order approximation to the variance of log earnings $(V L N)$. It therefore provides a natural starting point for extending the conventional $V L N$ measure that has been used in many previous studies of earnings inequality (e.g., Katz and Autor, 1999; Haider, 2001). ${ }^{17}$

We first derive a decomposition of the aggregate earnings inequality into betweenperson and within-person contributions. We then decompose both the withinperson and between-person components into sub-components attributable to intensive and extensive margin variation (i.e., differences in the probability of work versus differences in the amount of earnings conditional on working).

\footnotetext{
${ }^{17}$ See Levy and Murnane (1992) for a discussion of alternative measures of inequality.
} 


\subsection{Within and between person contributions to inequality}

Consider a balanced panel data setting where we observe the earnings $y_{i t}$ of a set of individuals $i=1, \ldots, N$ in periods $t=1, \ldots, T$. Let $\bar{y}_{t}$ represent mean earnings in period $t$ (including workers and non workers), and let $\bar{y}$ represent the grand mean of earnings across all years. In year $t$, the squared coefficient of variation in earnings is:

$$
C V_{t}^{2}=\left(\frac{1}{\bar{y}_{t}}\right)^{2} \frac{1}{N} \sum_{i}\left(y_{i t}-\bar{y}_{t}\right)^{2}=\frac{1}{N} \sum_{i}\left(\frac{y_{i t}-\bar{y}_{t}}{\bar{y}_{t}}\right)^{2} .
$$

The average squared coefficient across all years in the sample is:

$$
C V^{2}=\frac{1}{T} \sum_{t} C V_{t}^{2}=\frac{1}{N T} \sum_{t} \sum_{i}\left(\frac{y_{i t}-\bar{y}_{t}}{\bar{y}_{t}}\right)^{2} .
$$

And, for a given person the within-person squared coefficient of variation is:

$$
C V_{i}^{2}=\frac{1}{\left(\bar{y}_{i}\right)^{2}} \frac{1}{T} \sum_{t}\left(y_{i t}-\bar{y}_{i}\right)^{2}=\frac{1}{T} \sum_{t}\left(\frac{y_{i t}-\bar{y}_{i}}{\bar{y}_{i}}\right)^{2} .
$$

Notice that if there are only two observations per person, $C V_{i}^{2}$ is the squared arcpercent change in earnings of person $i$, which is a standard metric of volatility in the earnings instability literature.

Starting from the definition of $C V^{2}$ it is easy to show that it can be decomposed into the sum of a within-person component $(W)$, a between person component $(B)$, and a cross-term $(C)$, where 


$$
\begin{aligned}
W & =\frac{1}{N T} \sum_{t} \sum_{i}\left(\frac{\bar{y}_{i}}{\bar{y}_{t}}\right)^{2}\left(\frac{y_{i t}-\bar{y}_{i}}{\bar{y}_{i}}\right)^{2} \\
B & =\frac{1}{N T} \sum_{t} \sum_{i}\left(\frac{\bar{y}_{i}-\bar{y}_{t}}{\bar{y}_{t}}\right)^{2} \\
C & =\frac{2}{N T} \sum_{i} \sum_{t} \frac{\left(y_{i t}-\bar{y}_{i}\right)\left(\bar{y}_{i}-\bar{y}_{t}\right)}{\bar{y}_{t}^{2}}
\end{aligned}
$$

Expanding the expression for $W$, we get:

$$
\begin{aligned}
W & =\frac{1}{N} \sum_{i}\left(\frac{\bar{y}_{i}}{\bar{y}}\right)^{2}\left\{\frac{1}{T} \sum_{t}\left(\frac{\bar{y}}{\bar{y}_{t}}\right)^{2}\left(\frac{y_{i t}-\bar{y}_{i}}{\bar{y}_{i}}\right)^{2}\right\} \\
& \approx \frac{1}{N} \sum_{i}\left(\frac{\bar{y}_{i}}{\bar{y}}\right)^{2} C V_{i}^{2} \equiv W^{*}
\end{aligned}
$$

Assuming that $\bar{y}_{t}$ is relatively stable over time (i.e., $\left.\bar{y}_{t} \approx \bar{y}\right), W \approx W^{*}$ and the within-person component can be expressed as a weighted sum of $C V_{i}^{2}$ terms, where the weight for person $i$ is the squared ratio of their average earnings to overall average earnings.

Similarly, the between person component can be expressed as

$$
B=B^{*}+\frac{1}{T} \sum_{t}\left(\frac{\bar{y}_{t}-\bar{y}}{\bar{y}_{t}}\right)^{2}
$$

where

$$
B^{*} \equiv \frac{1}{N T} \sum_{i} \sum_{t}\left(\frac{\bar{y}_{i}-\bar{y}}{\bar{y}}\right)^{2} \times\left(\frac{\bar{y}}{\bar{y}_{t}}\right)^{2}
$$

Note that when $\bar{y}_{t} \approx \bar{y}, B \approx B^{*}$. In this case $B$ is approximately the squared proportional deviation between $\bar{y}_{i}$ and $\bar{y}$, and provides a simple measure of the 
dispersion in "permanent earnings" across individuals in the sample.

Finally, letting $\delta_{t}=\bar{y}_{t}-\bar{y}$ and $\delta_{i t}=y_{i t}-\bar{y}_{i}$ represent the deviations of average and individual earnings from their means over time, respectively, the cross term can be written as:

$$
C=\frac{2}{N T} \sum_{i} \sum_{t} \frac{\delta_{i t}\left(\bar{y}_{i}-\bar{y}\right)}{\bar{y}_{t}^{2}}-\frac{2}{N T} \sum_{i} \sum_{t} \frac{\delta_{i t} \delta_{t}}{\bar{y}_{t}^{2}} .
$$

The first term in this expression is very small in our setting, so the cross term is dominated by the second term, which depends on the covariance over time between individual and average earnings. As we show below, $C$ is always negative but is relatively small in the two later cohorts.

\subsection{Intensive and extensive margin contributions}

Next, we consider how the within- and between-person components, $W$ and $B$, can be decomposed into contributions representing intensive and extensive margin variation.

Within-person Let $p_{i}$ represent the average employment rate of individual $i$ (i.e., the fraction of years in which they have positive earnings), let $\bar{y}_{i}^{c}$ represent their mean earnings conditional on employment, and note that $\bar{y}_{i}=p_{i} \bar{y}_{i}^{c}$. A few simple substitutions establish that, for individuals with at least one year of positive earnings (i.e., those with $p_{i}>0$ ):

$$
C V_{i}^{2}=\frac{1}{T} \sum_{t}\left(\frac{y_{i t}-\bar{y}_{i}}{\bar{y}_{i}}\right)^{2}=\frac{1}{p_{i}}\left(C V_{i}^{c}\right)^{2}+\frac{1-p_{i}}{p_{i}}
$$


where $\left(C V_{i}^{c}\right)^{2}$, the conditional squared coefficient of variation, is defined as:

$$
\left(C V_{i}^{c}\right)^{2}=\frac{1}{T_{i}^{+}} \sum_{y>0}\left(\frac{y_{i t}-\bar{y}_{i}^{c}}{\bar{y}_{i}^{c}}\right)^{2}
$$

and $T_{i}^{+}=p_{i} T$ is the number of years of positive work by $i$. (For people who never work, $\left.C V_{i}=0\right)$. Equation (7) decomposes $C V_{i}^{2}$ into an intensive margin component that depends on $C V_{i}^{c}$ and an extensive-margin term that depends on $p_{i}$

Using the approximation for $W$ in equation (5) above, we can write:

$$
W \approx W^{*}=\frac{1}{N} \sum_{i}\left(\frac{\bar{y}_{i}}{\bar{y}}\right)^{2} C V_{i}^{2}=W^{i n t}+W^{e x t}
$$

where

$$
\begin{aligned}
W^{i n t} & =\frac{1}{N} \sum_{i}\left(\frac{\bar{y}_{i}}{\bar{y}}\right)^{2} \frac{1}{p_{i}}\left(C V_{i}^{c}\right)^{2}, \\
W^{\text {ext }} & =\frac{1}{N} \sum_{i}\left(\frac{\bar{y}_{i}}{\bar{y}}\right)^{2} \frac{1-p_{i}}{p_{i}} .
\end{aligned}
$$

These are just weighed sums of the person-specific intensive and extensive margin components of $C V_{i}^{2}$, where the weight depends on $\bar{y}_{i} / \bar{y}$. In a population of people who always work $W^{e x t}=0$, and $W=W^{\text {int }}$ is just a weighted average of individualspecific coefficients of variation of earnings.

Between-person Using another simple substitution we can we can decompose $B^{*}$, the main term in the between-person component of overall inequality, as:

$$
B^{*}=B^{e x t}+B^{\text {int }}+B^{\text {cross }}
$$


where

$$
\begin{aligned}
& B^{\text {ext }}=\frac{1}{N T} \sum_{i} \sum_{t}\left(\frac{\bar{y}}{\bar{y}_{t}}\right)^{2}\left(\frac{\bar{p}_{i}-\bar{p}}{\bar{p}}\right)^{2}\left(\frac{\bar{y}_{i}^{c}}{\bar{y}^{c}}\right)^{2}, \\
& B^{\text {int }}=\frac{1}{N T} \sum_{i} \sum_{t}\left(\frac{\bar{y}}{\bar{y}_{t}}\right)^{2}\left(\frac{\bar{y}_{i}^{c}-\bar{y}^{c}}{\bar{y}^{c}}\right)^{2}, \\
& B^{\text {cross }}=\frac{2}{N T} \sum_{i} \sum_{t}\left(\frac{\bar{y}}{\bar{y}_{t}}\right)^{2}\left(\frac{\bar{y}_{i}^{c}}{\bar{y}^{c}}\right)\left(\frac{\bar{y}_{i}^{c}-\bar{y}^{c}}{\bar{y}^{c}}\right)\left(\frac{\bar{p}_{i}-\bar{p}}{\bar{p}}\right) .
\end{aligned}
$$

Assuming that the gap between $B$ and $B^{*}$ is small (as it is in our samples), these three terms summarize the extension-margin component, the intensive margin component, and a joint covariance component of the overall between-person component of earnings inequality. Note that $B^{\text {cross }}$ depends on the (weighted) covariance between $\bar{y}_{i}^{c}-\bar{y}^{c}$ and $\bar{p}_{i}-\bar{p}$. This term will be larger, the greater the degree of "positive selection" among people with higher average probabilities of work.

In the absence of extensive margin variation, $\bar{p}_{i}=1, \bar{y}_{i}^{c}=\bar{y}_{i}$, and $\bar{y}^{c}=\bar{y}$. In this case $B^{e x t}=B^{\text {cross }}=0$, and

$$
B=\frac{1}{N T} \sum_{i} \sum_{t}\left(\frac{\bar{y}}{\bar{y}_{t}}\right)^{2}\left(\frac{\bar{y}_{i}-\bar{y}}{\bar{y}}\right) \approx \frac{1}{N} \sum_{i}\left(\ln \bar{y}_{i}-\overline{\ln y}\right)^{2} .
$$

In other words, when the population of interest is always employed, the between component of $C V^{2}$ is (approximately) the between-person variance in average log earnings. 


\subsection{Measuring the changes in intensive and extensive mar- gin contributions}

With this setup we turn to the estimates in Table 2, which quantify the various components of overall earnings inequality for women in our three 10-year panels. For comparative purposes we also show the same components for males in three parallel panels. For reference, Appendix Table 2 presents some descriptive summary statistics for the men in our three male panels.

The entries in the first panel of Table 2 show the overall value of $C V^{2}$ for each cohort and the within-person, between-person, and cross terms in equation (4) . We also show the value of the approximation given by equation (5) for the withinperson component of inequality. Comparisons of the various terms for our three cohorts, and between women and men, lead to four main conclusions. First, total earnings inequality as measured by the squared coefficient of variation is substantially greater for women than men. Second, overall inequality falls dramatically between the three panels for women but rises somewhat for men. Third, for both men and women the between-person component represents about $80 \%$ of overall earnings inequality, with a slight decline across the panels for both genders. Finally, the approximation in equation (5) is very good for all cohorts and genders except the 1968-77 cohort of females. Women in this cohort experienced relatively large increases in average earnings during the 10-year period they were observed in our data, leading to a slight departure between $W$ and $W^{*}$.

The rows in the second panel of Table 2 present the extensive and intensive margin components of $W^{*}$ as specified by equation (8). We see that for women, both the extensive-margin and intensive-margin components of within-person inequality 
fell between the cohorts, with a proportionally larger reduction in the extensive margin component. Consequently, the share of overall inequality attributable to within-person/extensive margin variation fell from $9 \%$ in the 1968-77 cohort to $6 \%$ in the 1988-97 cohort. In contrast, for men, the extensive margin component is very small across all three cohorts, contributing only $2-4 \%$ of overall earnings inequality. For men, however, we do see some rise in the within-person/intensive margin component, implying that earnings instability rose somewhat across the three cohorts in our sample. Nevertheless, the share of overall earnings inequality attributed to this component is relatively stable (16\% in the first panel, $20 \%$ in the second).

The rows in the bottom panel of Table 2 present the three components of $B^{*}$ specified by equation (8), as well as the deviation $B-B^{*}$ attributable to variation in $\bar{y}_{t}$ within each panel (see equation 6), which is relatively small. Here the contrasts between women and men are even larger. For women, we see that $B^{\text {ext }}$, the between-person/extensive margin component of inequality, fell in magnitude from 0.40 to 0.08 . This decline accounts for nearly $40 \%$ of the overall decline in $C V^{2}$ between the earliest and latest cohort. For men, by comparison, the betweenperson/extensive margin component of inequality is very small and stable in size, accounting for $2 \%$ of overall earnings inequality in each panel.

For women we also see a relatively large decline between cohorts in $B^{\text {cross }}$, which depends on the covariance between $\bar{y}_{i}^{c}-\bar{y}^{c}$ and $\bar{p}_{i}-\bar{p}$. Together, the decline in $B^{e x t}$ and $B^{\text {cross }}$ account for about two-thirds of the overall decline in $C V^{2}$ between the 1968-77 and 1988-97 cohorts of women.

Finally, we also see a decline in the between-person/intensive margin component $B^{\text {int }}$ for women between the three cohorts. Relative to the other components 
of $C V^{2}$, however, the proportional change in $B^{i n t}$ was smaller. Consequently, the share of overall earnings inequality among women attributed to differences in mean earnings conditional on working rose from $33 \%$ to $50 \%$. Among men in our three cohorts, $B^{\text {int }}$ rose in magnitude, but at a slower rate than the within-person/intensive margin component $\left(W^{i n t}\right)$, so the share of overall earnings variation attributable to $B^{\text {int }}$ fell slightly, from $74 \%$ to $68 \%$.

The relative size of the five main components of $C V^{2}$ for the 1968-77 and 1988-97 panels of women are summarized in Figure 6. For comparative purposes we also summarize the same components using samples that exclude the SEO subsample, and that use the overall PSID samples but reweight the samples to have the same joint distribution of age, education, and fraction black as the Current Population Survey (for the same calendar years). Reassuringly, the main features of the decomposition are similar regardless of whether we exclude the SEO or reweight our overall sample. ${ }^{18}$

The figure highlights two main conclusions from our decomposition exercise. First, overall female earnings inequality as summarized by the squared coefficient of variation fell by nearly 50\% between the 1968-77 and 1988-97 cohorts. Second, a relatively large share of the decline in earnings inequality was due to a decline in the magnitude of the extensive margin components of inequality. For example, using our main PSID samples, the combined extensive margin components (including $W^{e x t}, B^{e x t}$, and the covariance term $B^{\text {cross }}$ ) fell from 0.99 to 0.31 , accounting for about $80 \%$ of the overall decline in $C V^{2}$.

\footnotetext{
${ }^{18}$ In Appendix Table 3 we present a parallel analysis to Table 2, using the non-SEO samples. A comparison of the results with and without the SEO suggests that the relative shares of the variance components are quite similar.
} 


\section{Modeling earnings dynamics}

\subsection{Modeling intensive and extensive margin dynamics}

At the micro-econometric level there has been relatively little research attempting to model both the extensive and intensive margins of earnings variation. Three recent papers present relatively sophisticated intertemporal choice models of consumption and labor supply that incorporate variation in earnings at the extensive margin. Low et al. (2010) focus on men, allowing heterogeneity between education and age groups but not within these groups. Their approach thus cannot address issues related to overall earnings inequality. Altonji et al. (2013) model both the intensive and extensive margins of earnings determination for men, using a "semi-structural" model of hours and employment with a simplified specification of behavioral responses to current wage opportunities. Interestingly, Altonji et al. (2013) find that these behavioral responses are quite small - a conclusion that suggests it may be relatively costless to ignore them, as is implicitly done in much of the consumption and inequality literature. Finally a recent study by Eckstein and Lifshitz (2011) focuses on inter-cohort trends in labor force participation of women, with little direct attention on earnings.

Rather than incorporating both intensive and extensive margins of earnings variation, most of the existing literature has focused on either the intensive margin of male earnings dynamics, or on the extensive margin of female employment dynamics. Early studies of the longitudinal structure of US male earnings by MaCurdy (1982) and Abowd and Card (1989) led to the characterization of earnings as consisting of an individual-specific non-stationary (random walk) permanent component of earnings, a low-order stationary autoregressive moving- 
average (ARMA) transitory component, and a purely transitory component which is typically interpreted to represent classical measurement errors (see Meghir and Pistaferri, 2011). A non-stationary representation of the permanent component of earnings is often preferred conceptually because it captures the "permanent income hypothesis" formulation of expected lifetime earnings. It is also useful statistically because the variance of individuals' earnings tend to increase over the life cycle.

Similarly, the extensive margin literature on female employment dynamics has built on a series of papers by Heckman (Heckman, 1978, Heckman, 1981), that established the now-standard approach to modeling employment dynamics as combining state dependence - often through a first order Markov process - and underlying heterogeneity that can include persistent and transitory unobserved factors. Typically in this literature researchers find that family-based influences, including the presence of young children and spousal earnings, exert some influence on extensive margin choices of women.

Our approach is to build on these two literatures, specifying a dynamic participation equation with state dependence and unobserved heterogeneity and a model of log earning conditional on work that incorporates permanent and transitory components. In contrast to much of the literature on earnings dynamics, however, we explicitly model the effects of family-based factors on earnings conditional on work. 


\subsection{A model for the extensive and intensive margins of earnings}

On the extensive margin, we specify a dynamic panel data model for the event that individual $i$ is observed working in year $t\left(E_{i t}=1\right)$ that includes a first-order dynamic binary response model for $t=2 \ldots 10$, and a reduced-form specification for the initial condition in $t=1$ :

$$
\begin{aligned}
& E_{i 1}=1\left(X_{e i 1}^{\prime} \beta_{e 0}+\epsilon_{e i 1}>0\right), \\
& E_{i t}=1\left(\gamma E_{i t-1}+X_{e i t}^{\prime} \beta_{e}+\epsilon_{e i t}>0\right), t=2, \ldots, 10 .
\end{aligned}
$$

As explained in more detail below, the vectors $X_{\text {eit }}$ include a set of individual and family characteristics that we take as exogenous determinants of the probability of employment in each year, including the first year of the panel. We assume that the latent error components are all normally distributed so the employment model amounts to a dynamic probit model.

For the intensive margin, we specify a standard log-linear specification for latent earnings $\left(Y_{i t}^{*}\right)$, which are realized as observed earnings $\left(Y_{i t}\right)$ conditional on employment:

$$
\begin{aligned}
& Y_{i t}^{*}=X_{y i t}^{\prime} \beta_{y}+\epsilon_{y i t}, t=1, \ldots, 10 ; \\
& Y_{i t}=E_{i t} . Y_{i t}^{*} .
\end{aligned}
$$

As discussed below, we assume that the vector $X_{\text {yit }}$ includes all the characteristics included in $X_{\text {eit }}$ plus the logarithm of real median earnings in the economy (interacted with individual education) to capture within-panel trends in real earnings growth. 
Following the literature on EGF's for males (e.g. Abowd and Card, 1989; Meghir and Pistaferri, 2004), we assume that $\epsilon_{y i t}$ consists of a "permanent" component $\left(\alpha_{y i t}\right)$ that follows a random walk and a "transitory" component $\left(u_{y i t}\right)$ that is a stationary MA(1). Recognizing that our samples include individuals at different stages of their life cycles, we allow the variance in the initial period permanent component of latent earnings, $\alpha_{y i 1}$, to vary with age in period $1\left(a_{g} e_{i 1}\right)$. We adopt a parallel specification for the error terms in the employment model. Specifically we assume that $\epsilon_{\text {eit }}$ consists of a person-specific random walk component and a stationary $\mathrm{MA}(1)$ component, and allow the variance in $\alpha_{e i 1}$, the initial period permanent component of the employment determination model, to vary linearly with age.

To account for potential non-random selectivity of employment and correlated shocks to employment and earnings, we also allow each of the respective error components of the employment and earnings equations to be contemporaneously correlated. Specifically, for $j=e, y$ we assume:

$$
\begin{aligned}
& \epsilon_{e i t}=\alpha_{e i t}+u_{e i t}, t=2, \ldots, 10 \\
& \epsilon_{y i t}=\alpha_{y i t}+u_{y i t}, t=1, \ldots, 10 \\
& \alpha_{j i t}=\alpha_{j i t-1}+\eta_{j i t}=\alpha_{j i 1}+\Sigma_{s=2}^{t} \eta_{j i s} ; t=2, \ldots, 10 \\
& \alpha_{j i 1} \sim N\left(0, \sigma_{\alpha j 1}^{2}\right), \sigma_{\alpha j 1}^{2}=\sigma_{\alpha j 0}^{2}+\sigma_{\alpha j}^{2} *\left(a g e_{i 1}-24\right) \\
& \eta_{j i s} \sim N\left(0, \sigma_{\eta j}^{2}\right) ; t=2, \ldots, 10 \\
& u_{j i t}=\theta_{j} \omega_{j i t-1}+\omega_{j i t} ; t=1, \ldots, 10 \\
& \omega_{j i t} \sim N\left(0, \sigma_{\omega j}^{2}\right) ; t=0, \ldots, 10 \\
& \rho_{\alpha}=\operatorname{corr}\left(\alpha_{e i 1}, \alpha_{y i 1}\right), \rho_{\eta}=\operatorname{corr}\left(\eta_{e i t}, \eta_{y i t}\right), \rho_{\omega}=\operatorname{corr}\left(\omega_{e i t}, \omega_{y i t}\right) .
\end{aligned}
$$


To deal with the initialization of the Markov process for employment we also assume that $\epsilon_{e i 1}$, the first-period employment shock, consists of the initial permanent component $\left(\alpha_{e i 1}\right)$, modified by a factor loading $\left(\delta_{e 1}\right)$, plus a transitory error component $\left(u_{e i 1}\right)$ :

$$
\epsilon_{e i 1}=\delta_{e 1} \alpha_{e i 1}+u_{e i 1}
$$

For identification, we normalize the employment equation's initial-period total error variance to 1 . Specifically, we set $\sigma_{\alpha e 1}^{2}+\sigma_{u e}^{2}=1$, so that $\sigma_{u e}^{2}=\left(1+\theta_{e}^{2}\right) \sigma_{\omega e}^{2}=$ $1-\sigma_{\alpha e 1}^{2} \cdot 19$

Finally, because the distributions of log earnings for women in our samples show evidence of bi-modality (reflecting the presence of both full-time and parttime workers), we actually allow the earnings equation errors to be a mixture of two underlying normally distributed errors, each of which follows the dynamic process specified in (12). ${ }^{20}$ We adopt a relatively parsimonious formulation for the error components, allowing the means of the two underlying normal distributions to differ, but restricting the variances of both the permanent and transitory components to vary by the same scale parameter. Specifically, we specify that the error component in earnings, $\epsilon_{y i t}$, is the sum of two normally distributed shocks that are themselves each a combination of a persistent and a transitory component:

$$
\epsilon_{y i t}=(1-\phi) \epsilon_{y i t}^{0}+\phi \epsilon_{y i t}^{1},
$$

\footnotetext{
${ }^{19}$ Note that this normalization is applied to the $(\mathrm{t}=1)$ (latent) structural error term, $\alpha_{e i 1}+u_{e i 1}$, whose components are part of the permanent random walk and transitory MA(1) components respectively.

${ }^{20}$ An alternative would be to attempt to classify workers in each year as part-time or fulltime and extend the discrete choice model for employment to model the choice between these alternatives, possibly allowing for part-year employment as well.
} 
where $\epsilon_{y i t}^{k}=\alpha_{y i t}^{k}+u_{y i t}^{k}(k=0,1)$, as in equation (12); $\epsilon_{y i t}^{0} \sim N\left(0, \sigma_{\epsilon y 0}^{2}\right)$; and $\epsilon_{y i t}^{1} \sim N\left(\mu_{y 1}, \delta_{y 1} \sigma_{\epsilon y 0}^{2}\right)$, and the variance scale parameter $\delta_{y 1}$ is the same for both the permanent $\left(\alpha_{y i t}^{1}\right)$ and transitory $\left(u_{y i t}^{1}\right)$ error components of $\epsilon_{y i t}^{k}$. This adds three additional parameters to the model: $\left(\phi, \mu_{y 1}, \delta_{y 1}\right)$.

\subsection{Specification of controls}

A final specification issue is the choice of control variables to include in the pair of vectors $\left(X_{e i t}, X_{y i t}\right)$. Both vectors include education, a dummy for black race, a quadratic function of age, and the aggregate unemployment rate. We also include a relatively rich set of family variables, with both current period variables and averages of these variables across the 10 years of the panel. Specifically, we include:

- a dummy for living with a partner (i.e., being classified as a "wife" in the PSID survey) in the current year, and the mean of this variable over all 10 years

- a dummy for whether the partner (if present) is currently employed, the mean of this variable over all years that a partner is present, and a dummy for having a partner who is never employed

- partner's mean log earnings (over the years a partner is present) and the current year deviation of partner's log earnings from partner's mean log earnings

- the current number of children living with the woman and the average of this variable over all 10 years

- a dummy for whether there is any co-resident child under 5 and the average of this variable over all 10 years

- a dummy for whether there is any co-resident child age 6-17 and the average of this variable over all 10 years 
Note that we construct averages across the partner variables for a given women without accounting for the possibility that the woman is observed with two or more partners (although this is relatively rare). Effectively, we are assuming that the specific identity of different partners does not matter.

For the model for employment in the first year of the panel we include the same variables (apart from the contemporaneous unemployment rate). Finally, as noted above, in the earnings models we also include the log of median earnings in the economy, and interactions of this variable with dummies for women with exactly 12 years of schooling, 13-15 years of schooling, and 16+ years of schooling. These variables are meant to capture economy-wide wage trends that may differ by education group, and are potentially important as we do not include year dummies.

\section{Results}

\subsection{Estimation results}

The model is estimated using maximum simulated likelihood (MSL) estimation, with 20 simulation replications. The results of the estimation are summarized in Table 3. Panel a of the table presents the estimated coefficients for the employment

and $\log$ (earnings) equations for each of the three 10 -year panels (i.e., $\widehat{\beta}_{e}$ and $\widehat{\beta}_{y}$ ); panel b shows the error components parameter estimates for each model; and the estimated initial conditions employment equation coefficients $\left(\widehat{\beta}_{e 0}\right)$ are presented in the Appendix Table 4.

Effects of observed factors Focusing first on covariate estimates, we find large positive effects of lagged employment status on the probability of employment (i.e., 
the coefficient $\gamma$ in equation (10)). The estimated state dependence effect is slightly larger in the 1968-77 panel than in the two later panels. The magnitude of $\widehat{\gamma}$ for the first cohort suggests that other things equal, women who worked last year are about 70 percentage points more likely to work in the current year; for the later cohorts the impact is about 60 percentage points. ${ }^{21}$

Focusing next on the child-related variables, the largest coefficients are the ones representing the effects of a having child under the age of 5 on the probability of employment. Translating the estimated probit coefficients to marginal effects at the sample means for each cohort, the implied effects are -10.4 percentage points for the 1968-77 cohort, -7.7 percentage points for the 1978-98 cohort, and -4.3 percentage points for the 1988-97 cohort. $^{22}$ We see a similar diminution in the effect of young children in the initial conditions model for employment in the first year of each panel, from an implied average marginal effect of -27.6 percentage points for the first cohort to -13.6 percentage points for the last cohort. In contrast, the presence of older children has no significant effect on the probability of employment.

The effects of the partner-related variables are harder to assess because the presence of a partner "turns on" a whole set of variables simultaneously, including the partner dummy, the average employment probability of the partner, the average log earnings of the partner, and the dummy for whether the partner is

\footnotetext{
${ }^{21}$ Some decline in state dependence is evident from the simple comparisons of probabilities of employment conditional on employment status in the previous two years in Table 1 . In the 1968-77 panel, $P\left(E_{i t}=1 \mid E_{i t-1}=1, E_{i t-2}=0\right)-P\left(E_{i t}=1 \mid E_{i t-1}=0, E_{i t-2}=1\right)=0.36$ (i.e., a 36 percentage point higher employment rate if employed last year than if not, conditional on 1 year of work in the previous 2 years) whereas in the 1988-97 panel this gap falls to 27 points. Note that these simple comparisons make no adjustments for the effects of the covariates, or for correlation in the time-varying error component of employment determination.

${ }^{22}$ The conversion factors are roughly $0.40 \times$ the coefficients for the $1968-77$ panel, $0.33 \times$ the coefficients for the 1978-87 panel, and $0.29 \times$ the coefficients for the 1988-97 model.
} 
employed (which is nearly always 1). Taking account of the joint effects of these variables, however, the impacts of the partner variables fall in magnitude across the panels. For example, the implied marginal effect on the probability of employment of moving from unmarried to married status with an "average" spouse is about -35 percentage points for women in the 1968-77 cohort, but -27 percentage points for those in the $1988-97$ cohort. $^{23}$

Beyond the family-related variables, the other socio-demographic variables have reasonably predictable patterns. Education has positive effects on both employment and earnings, with increasingly larger effects in later cohorts. The estimated age effects imply that the age profiles of the probability of work and of earnings conditional on work both became steeper between ages 24 and 45 for later cohorts, consistent with other literature showing rises in the return to potential experience for women between the 1960s and 1980s (e.g., Light and Ureta, 1995; Blau and Kahn, 2017). Black race has a slightly negative effect on the probability of employment, with little change across the cohorts. ${ }^{24}$ In contrast, the effect of black race on earnings conditional on work shifted from a relatively large negative effect in the first cohort to a small and statistically insignificant in the later cohorts.

Finally, looking at the macro-level variables, the models show an increasingly negative effect of the unemployment rate on the probability of work, suggesting that women's employment has become more cyclical over time. In the first panel there is strong positive relationship between earnings for women who work and

\footnotetext{
${ }^{23}$ The implied marginal effects of moving to married status with a partner whose mean log earnings are only $50 \%$ of the average, and has a $85 \%$ average employment rate (rather than a 95\% rate) are smaller: a -29 percentage point effect for our earliest cohort and a -21 percentage point effect for our latest cohort.

${ }^{24}$ We note that about two-thirds of black women in our combined sample were in the SEO subsample, so black race includes an effect associated with being drawn from the SEO subsample.
} 
economy-wide median earnings. This correlation diminishes across the panels, particularly for less-educated women.

Error structure Next we briefly summarize the dynamic error structure of the model. We find statistically significant permanent and transitory error components in both the employment and earnings equations, with a positively correlated MA1 transitory error in earnings $\left(\theta_{y} \approx 0.25\right)$ but a negatively correlated MA1 transitory error in the latent determinants of employment $\left(\theta_{e} \approx-0.5\right) .{ }^{25}$ Shocks to the permanent components in the two equations are positively correlated, particularly for the first year observation (i.e., the initial condition), but the correlation declines across the three panels. Specifically, the estimates of $\operatorname{correl}\left(\alpha_{e i 1}, \alpha_{y i 1}\right)$ decline from 0.69 in the first panel to 0.55 in the third panel, whereas correl $\left(\alpha_{e i t}, \alpha_{y i t}\right)$ declines from 0.33 to 0.13 across the three panels. The positive correlations between $\alpha_{\text {eit }}$ and $\alpha_{y i t}$ imply that unobserved but highly persistent factors that cause a woman to be more likely to work also increase her average earnings if she works (i.e., "positive selection" on the unobserved permanent error components). The degree of positive selection, however, is declining across the three cohorts.

In contrast to the permanent shocks, the shocks to the transitory components of latent employment and earnings are negatively correlated. The correlation between these components is also declining in magnitude over time (from -0.37 in the first panel to -0.21 in the third). Finally, our estimates imply that the variances of the initial permanent components of employment and earnings are both increasing with age (i.e., the estimates of the trend coefficients in the initial variances, $\sigma_{\alpha e}^{2}$

\footnotetext{
${ }^{25}$ Although the negatively correlated MA1 errors components in employment are unusual, similar results have been found in the literature on female employment dynamics in models that include state dependence, and permanent and transitory errors (e.g. Hyslop, 1999)
} 
and $\sigma_{\alpha y}^{2}$, are positive) as is predicted by human capital models with unobserved investments (e.g., Mincer, 1974).

To help understand the dynamic contributions of the various permanent and transitory error components to the evolution of employment and $\log$ (earnings), we conducted a series of simulations of the effects of shocks to each of the components of the error structure. ${ }^{26}$ Given that the employment and earnings error components are correlated, a primitive shock to one dimension will generate a correlated shock in the other dimension that leads to persistent "cross effects". Appendix Figures 3 and 4 show the impacts of a one standard deviation shock to each of the 3 error components of employment and earnings, respectively. The top panels of each figure show the responses of future employment probabilities (left side) and mean log earnings (right side) to a shock in the initial permanent error components $\left(\alpha_{e i 1}\right.$ and $\left.\alpha_{y i 1}\right)$. The middle panels show the responses to a shock to the permanent error component in year $2\left(\alpha_{e i 2}\right.$ and $\left.\alpha_{y i 2}\right)$. Finally, the bottom panels show the responses to shocks in the transitory error components in year $1\left(\omega_{e i 1}\right.$ and $\left.\omega_{y i 1}\right)$. Each panel shows the response functions from the models for each of our three cohorts, allowing us to assess whether reactions to unobserved determinants of employment and earnings have changed between cohorts.

We find that overall shapes of the response functions are fairly similar for the three PSID cohorts. In particular, looking down the three panels on the left side of Appendix Figure 3, the dynamic responses of future employment to

\footnotetext{
${ }^{26}$ In particular, we simulate the baseline model specification using random draws for each component, and then add $+/-0.5$ standard deviation shocks for each component in turn, and estimate the average difference in the employment and earnings outcomes over time. The shocks were 1 standard deviation shocks to the age-adjusted initial permanent stock components; 1 standard deviation shocks to the period-2 random walk innovations; and 1 standard deviation shocks to the period-1 transitory MA innovations.
} 
shocks in the three different error components in employment are very similar across cohorts. Thus, the extensive margin responses to unobserved determinants of employment do not appear to have changed much across cohorts, despite the rapid rise in the fraction of women who work. The "cross-effects" of permanent shocks to employment on future earnings have moderated somewhat between the three cohorts, as shown in panel e of Appendix Figure 3. This is consistent with some weakening of the degree of positive selectivity in the subgroup of women who work.

The panels on the right side of Appendix Figure 4 show that the effects of shocks to the permanent and transitory error components of earnings have relatively similar effects on future earnings, suggesting that the intensive margin responses to unobserved determinants of earnings are similar across cohorts. Similarly, the "cross effects" of shocks to earnings on future employment probabilities, shown in the three panels on the left side of Appendix Figure 4, are fairly similar across cohorts. Overall, our interpretation is that apart from some weakening of the correlation between the persistent shocks to earnings and employment, which largely determine the selectivity of the subset of workers with respect to their unobserved earnings potential, the dynamic error structure of employment and earnings is quite stable across the three cohorts.

\subsection{Model fit}

How well can our relatively simple model describe the the employment and earnings outcomes of women in our PSID samples, and the various components of earnings inequality? Figure 7 shows actual and predicted employment rates, mean log 
earnings for workers, and coefficients of variation of earnings $(C V)$ of earnings, for each year in our sample. (We also show predicted means and the $C V^{\prime} s$ of "potential" earnings, which we discuss in the next subsection).

Our model does a relatively good job of fitting the actual employment rates in our samples. It is somewhat less successful in predicting mean log earnings of those who work, with a general pattern of under-prediction that is worse in the later years of the first cohort, and (to a lesser degree) in the later years of third cohort. Our model also systematically under-predicts the overall coefficient of variation of earnings, with a 10-15 point gap on average across all three cohorts.

Table 4 presents a more detailed comparison between the actual and fitted components of inequality in each of the three cohorts, using the same decomposition strategy as in Table 2. We also show, in the two right-most columns of the table, the changes in the actual and predicted components of variance between the 196877 cohort and the 1988-97 cohort. In general, the model does a reasonable job of fitting the between-person components of inequality, but is less successful at fitting the within-person components. The poorest fit is for the within-person/intensive margin component, which is over-fit by a factor of $90 \%$ in the 1968-77 panel, $70 \%$ in the $1978-87$ panel, and $62 \%$ in the $1988-97$ panel. The positive bias in this component arises from the fact that our model has a very hard time matching both the mean and the variation in individual earnings, conditional on work. Because our models over-fit the within-person components for all three cohorts, however, the bias in predicting the change in overall inequality (i.e., the change in $C V^{2}$ ) between the first and third cohorts is relatively modest (around 7\%). 


\subsection{Changing selectivity of workers}

As noted in our discussion of the model specification, by allowing the error components in the models for employment and earnings to be correlated we address potential non-random selectivity in the distribution of latent earnings for women who choose to work. A simple way to assess the degree of non-random selectivity implied by our model is to compare mean predicted earnings for those who choose to work in a given year (which are shown in Figure 7b by the points labeled "Model Observed") versus the predicted mean earnings for all women (which are shown in Figure 7b by the points labeled "Model Potential"). As expected given the positive estimated correlations between the permanent components of the error processes for employment and earnings, mean predicted earnings for those who work are higher than mean predicted earnings for the entire sample. The average selectivity gap is $22 \log$ points for the first cohort, 18 log points for the second cohort, and 10 log points for the third cohort. The decreasing selectivity gap implies that the growth in mean log earnings among working women understates the growth in potential earnings among all women between the first and third cohorts by about 12 log points. This is a relatively large effect, amounting to about a 0.6 log point per year understatement of mean real earnings growth. ${ }^{27}$

Our model also implies a selectivity gap between the predicted coefficient of variation taking account of zero earnings for non workers (labeled as "Model Observed" in Figure 7c), and the predicted $C V^{\prime} s$ under the assumption that all women work (labeled as "Model Potential" in Figure 7c). As would be expected, the pre-

\footnotetext{
${ }^{27} \mathrm{~A}$ number of earlier studies, including Mulligan and Rubinstein (2008) and Jacobsen et al. (2015) have attempted to address the changing selectivity in hourly wages of female workers. Our results are not directly comparable because the selectivity in annual earnings incorporates both selectivity in wages and in hours of work.
} 
dicted $C V^{\prime} s$ assuming everyone works are substantially lower than the predicted CV's assuming selective work behavior, with an average gap of 0.46 for the 1968-77 cohort, 0.26 for the $1978-86$ cohort and 0.18 for the $1988-97$ cohort. The selectivity gaps in the squared coefficients of variation $\left(C V^{2}\right)$ are roughly twice as large: 1.12 for the first cohort, 0.54 for the second, and 0.35 for the third. The implication of this decreasing selectivity is that a significant fraction of the predicted decline in earnings inequality for women is attributable to a reduction in the extensive margin component of predicted inequality, as implied by the results in Table 4 .

\subsection{Implications for inequality: the changing effects of fam- ily}

We now use our estimated model to address the changing effects of family-related factors - specifically the presence of children in different ages and presence and characteristics of spouses/partners - on female earnings inequality. For simplicity, we focus on changes between our earliest cohort, who are observed between 1968 and 1977, and our latest cohort, who are observed between 1988 and 1997.

Effects of children Table 5a shows the results of a three alternative simulations of our model: the full simulation (already summarized in Table 4); a version of our model in which we "turn off" the direct effects of children in the current year (e.g., the dummy for having a child under 5 in the current year), but leave in place the effects of the average values of the child variables in our model, which capture differences in unobservable characteristics between women with no children and those with different average numbers of children during our panel; a version in which we turn off the effects of the average values of the child variables (which we 
call the "selection effects" of children) but leave in place the current-year direct effects; and a version in which we turn off all the child-related variables, effectively making each person childless in all years.

In general, both the direct and selection effects of children are larger in the early cohort. For example, in the first row of the table we see that in the 1968-77 cohort, the direct effects of children lower average employment by 7 percentage points (ppts) (from 66\% to 59\%), the selection effects lower average employment by a similar amount, and the combination lowers average employment rates by 14 ppts (from $73 \%$ to $59 \%$ ). In the 1988-97 cohort the corresponding impacts are all small: approximately 0 for the direct effects of children, -3 ppt for the indirect effects, and -2 ppts for the combined effect.

The net impacts of these changes are summarized in Table 5b. Again starting with the top row, we see that the actual change in average employment rates between the cohorts was 22 ppts, as was the predicted change in our full simulation. Taking away the direct effects of children the simulated increase would have been 14 ppts, taking away the selection effects of it would have been 18 ppts, and taking away all child factors it would have been 11 ppts. Thus, we infer that the changing effects of children account for $22-11=11$ ppts of the increase, or a $50 \%$ share of the simulated 22 ppt increase in employment.

Carrying out the same exercise for the change in $C V^{2}$ - our measure of overall earnings inequality - and its main components, the results in Table 5a and 5b suggest three conclusions. First, both the direct and selection effects of children increase earnings variation. Second, these effects were becoming smaller in the three decades we study. Third, as a result of the second factor, the gradual diminution of child-related factors has contributed to a narrowing of most components of female 
earnings inequality, with a typical "explained share" around 60 percent.

Effects of partner/spouse Table 6 shows the a parallel analysis for the effects of the partner variables included in our model. We simplify the analysis relative to Table 5a by simply comparing our full model simulation to a simulation from a model with all the spousal-related factors "turned off". In general, the results suggest that spouse-related factors are an important source of variation in female earnings, though again the effects are notably smaller for the later cohort. We emphasize that this is not a reflection of a fall in partnership rates: across our three cohorts the rate of marriage/partnering is quite stable at around $70 \%$ (see Table 1). Instead it reflects falling magnitudes for the impacts of the spouse-related variables.

Looking at the right-most column of Table 6 we see that spousal variables explain about $40 \%$ of the rise in employment rates between the 1968-77 cohort and the 1988-97 cohort, and close to $60 \%$ of the rise in overall earnings inequality, with similar explained shares of most of the main components of changing inequality.

Combined effects of family-related factors Finally, in Table 7 we show the results from a simulation in which we "turn off" all child-related and spouse-related variables - essentially assuming that all the women in all three cohorts were single heads with no children. The combined effects of the two sets of variables are quite large for the 1968-78 cohort. For example, the model suggests that average employment rates of women would have been $82 \%$ in the absence of these factors - nearly the same as the actual average employment rate of women in our 1988-97 cohort. By the third cohort the combined variables are still working in the same 
direction, but their net effects are far smaller. Thus, we conclude that the changing effects of children and spouse-related variables can account for about $70 \%$ of the rise in average employment rates.

A similar conclusion applies to $C V^{2}$, our overall measure of inequality. For the early cohort, the model suggests that $C V^{2}$ would have been only about one-half as large $(1.07 / 2.10)$ if we removed the effects of all the family variables. For the later cohort the implied change in overall inequality is relatively modest (0.95 versus 1.19). Thus, comparing the simulated changes with and without the effects of children and partners, we conclude that about $87 \%$ of the fall in overall earnings inequality between the earlier and later cohort can be explained by a diminishing effect of family-related variables on the labor supply choices of women.

\section{Concluding discussion}

In this paper we examine trends in the inequality of annual earnings among women in the U.S. Our starting point is the observation that to understand the evolution of earnings inequality among women, one needs to take account of changes in the probability of work - the extensive margin of earnings variation. We lay out a simple descriptive framework that allows us to partition overall inequality into within- and between-person components, and then show how these can be further decomposed into intensive-margin and extensive-margin components. In a population that always works the extensive margin components are zero; the withinperson/intensive margin component corresponds to the "transitory" component of individual earnings variation; and the between-person/extensive margin component corresponds to the "permanent" component of individual earnings variation. 
More generally, both the within-person and between-person components of earnings variation include an extensive margin component; while the between-person component also includes a "covariance" between the average level of earnings conditional on working and the average probability of work, reflecting the average selectivity of the working subpopulation.

Applying this framework to three cohorts of women from the PSID, observed 1968-77, 1978-87, and 1988-97, we show that overall inequality in female earnings has declined by about $50 \%$ between the early and late cohorts. A large share of the decline is attributable to reductions in the extensive-margin component, reflecting the rise the average probability of employment for women in the third cohort relative to the first.

We then extend the existing literature on earnings dynamics by introducing a statistical earnings generating function that combines a standard model for the evolution of individuals' latent earnings with a dynamic discrete choice model of employment. We incorporate a relatively rich specification of the effects of familyrelated variables in our models of employment and earnings, including both current period characteristics and average family characteristics that capture differences in unobserved preferences between women. Estimating the model separately by cohort we show that, apart from a reduction in the degree of positive selection of workers, the correlation structure of the unobserved components driving the probability of work and earnings conditional on work have not changed very much. Instead, the main difference in our models is in the diminishing effects of the family-related variables. This decline accounts for over $80 \%$ of the overall decline in female earnings inequality.

Our modeling framework is highly simplified, in that we take as given the num- 
ber and ages of co-resident children for each woman, and her marriage/partnership status in each year. We also make no attempt to separately model the determination of hours of work and wages per hour. Both of these issues would be important avenues for extending our findings in future research.

\section{References}

Abowd, J. M. and D. Card (1989). On the covariance structure of earnings and hours changes. Econometrica 57(2), 411-445.

Altonji, J. G., A. A. Smith, and I. Vidangos (2013). Modeling earnings dynamics. Econometrica 81(4), 1395-1454.

Baker, M. and G. Solon (2003). Earnings dynamics and inequality among canadian men, 1976-1992: Evidence from longitudinal income tax records. Journal of Labor Economics 21(2), 289-321.

Blau, F. D. and L. M. Kahn (2007). Changes in the labor supply behavior of married women: 1980-2000. Journal of Labor Economics 25(3), 393-436.

Blau, F. D. and L. M. Kahn (2017). The gender wage gap: Extent, trends, and explanations. Journal of Economic Literature 55(3), 789-865.

Celik, S., C. Juhn, K. McCue, and J. Thompson (2012). Recent trends in earnings volatility: Evidence from survey and administrative data. The BE Journal of Economic Analysis 83 Policy 12(2).

Dahl, M., T. DeLeire, and J. A. Schwabish (2011). Estimates of year-to-year volatility in earnings and in household incomes from administrative, survey, and matched data. Journal of Human Resources 46(4), 750-774.

DeBacker, J., B. Heim, V. Panousi, S. Ramnath, and I. Vidangos (2013). Rising 
inequality: transitory or persistent? new evidence from a panel of us tax returns. Brookings Papers on Economic Activity 2013(1), 67-142.

Eckstein, Z. and O. Lifshitz (2011). Dynamic female labor supply. Econometrica $79(6), 1675-1726$.

Fitzgerald, J., P. Gottschalk, and R. Moffitt (1998). The impact of attrition in the panel study of income dynamics on intergenerational analysis. Journal of Human Resources 33(2), 300-344.

Goldin, C. (1990). Understanding the gender gap: An economic history of American women. Oxford Press.

Gottschalk, P. and R. Moffitt (1994). The growth of earnings instability in the us labor market. Brookings Papers on Economic Activity 1994(2), 217-272.

Guvenen, F. (2007). Learning your earning: Are labor income shocks really very persistent. American Economic Review 97(3), 687-716.

Haider, S. J. (2001). Earnings instability and earnings inequality of males in the united states: 1967-1991. Journal of labor Economics 19(4), 799-836.

Heckman, J. J. (1978). Simple statistical models for discrete panel data developed and applied to test the hypothesis of true state dependence against the hypothesis of spurious state dependence. Annales de l'INSEE 30-31, 227-269.

Heckman, J. J. (1981). Heterogeneity and state dependence. In S. Rosen (Ed.), Studies in Labor Markets, pp. 91-139. Chicago and London: University of Chicago Press.

Hyslop, D. R. (1999). State dependence, serial correlation and heterogeneity in intertemporal labor force participation of married women. Econometrica 67(6), $1255-1294$.

Jacobsen, J., M. Khamis, and M. Yuksel (2015). Convergences in mens and womens 
life patterns: Lifetime work, lifetime earnings, and human capital investment. In S. W. Polacheck, K. Tatsiramos, and K. F. Zimmerman (Eds.), Gender Convergence in the Labor Market Research in Labor Economics Volume 41, Chapter 1, pp. 1-33. Emerald Group.

Juhn, C. and K. M. Murphy (1997). Wage inequality and family labor supply. Journal of labor economics 15(1), 72-97.

Katz, L. F. and D. H. Autor (1999). Changes in the wage structure and earnings inequality. Handbook of labor economics 3, 1463-1555.

Kopczuk, W., E. Saez, and J. Song (2010). Earnings inequality and mobility in the united states: Evidence from social security data since 1937. Quarterly Journal of Economics 125(1), 91-128.

Levy, F. and R. J. Murnane (1992). Us earnings levels and earnings inequality: A review of recent trends and proposed explanations. Journal of economic literature 30(3), 1333-1381.

Light, A. and M. Ureta (1995). Early-career work experience and gender wage differentials. Journal of Labor Economics 13(1), 121-154.

Low, H., C. Meghir, and L. Pistaferri (2010). Wage risk and employment risk over the life cycle. The American economic review 100(4), 1432-1467.

MaCurdy, T. E. (1982). The use of time series processes to model the error structure of earnings in a longitudinal data analysis. Journal of econometrics 18(1), $83-114$.

Meghir, C. and L. Pistaferri (2004). Income variance dynamics and heterogeneity. Econometrica 72(1), 1-32.

Meghir, C. and L. Pistaferri (2011). Earnings, consumption and life cycle choices. Handbook of Labor Economics 4, 773-854. 
Mincer, J. (1974). Schooling, experience and earnings. University of Chicago Press for NBER.

Mulligan, C. B. and Y. Rubinstein (2008). Selection, investment, and women's relative wages over time. The Quarterly Journal of Economics, 1061-1110.

Sabelhaus, J. and J. Song (2010). The great moderation in micro labor earnings. Journal of Monetary Economics 57(4), 391-403.

Shin, D. and G. Solon (2007). New evidence on real wage cyclicality within employer-employee matches. Scottish Journal of Political Economy 54(5), 648660.

Shin, D. and G. Solon (2011). Trends in men's earnings volatility: What does the panel study of income dynamics show? Journal of public Economics 95(7-8), 973-982.

Stevenson, B. and J. Wolfers (2007). Marriage and divorce: Changes and their driving forces? Journal of Economic Perspectives 21(2), 27-52.

Ziliak, J. P., B. Hardy, and C. Bollinger (2011). Earnings volatility in america: Evidence from matched cps. Labour Economics 18(6), 742-754. 
Figure 1: Standard Deviation of Log Annual Earnings

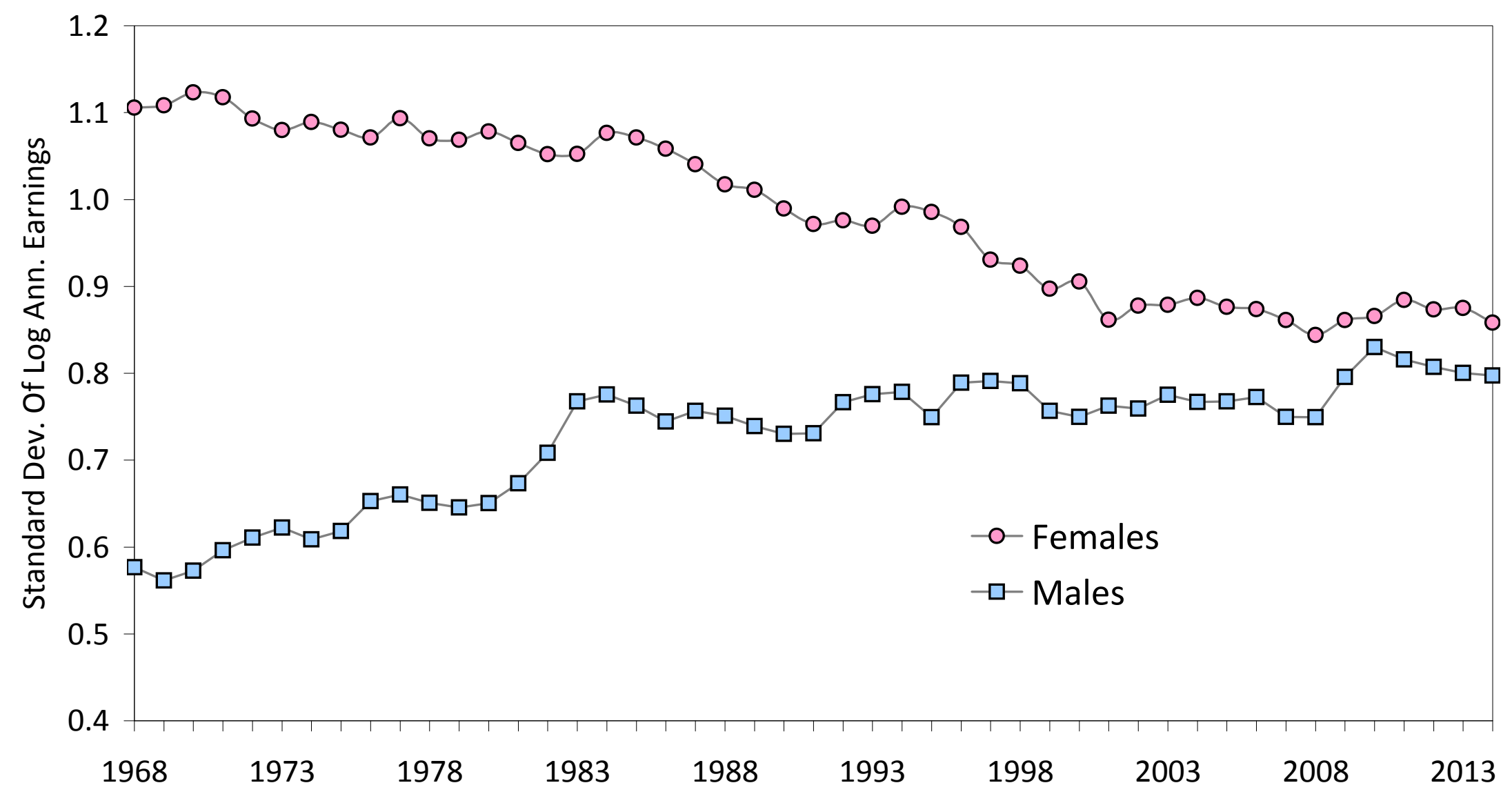

Note: sample restricted to individuals age 24-60 in all years. CPS sample weights are not used. Earnings are censored at 5th and 99th percentiles, with no adjustment for topcoding. 
Figure 2: Real Mean Annual Earnings of Females in March CPS

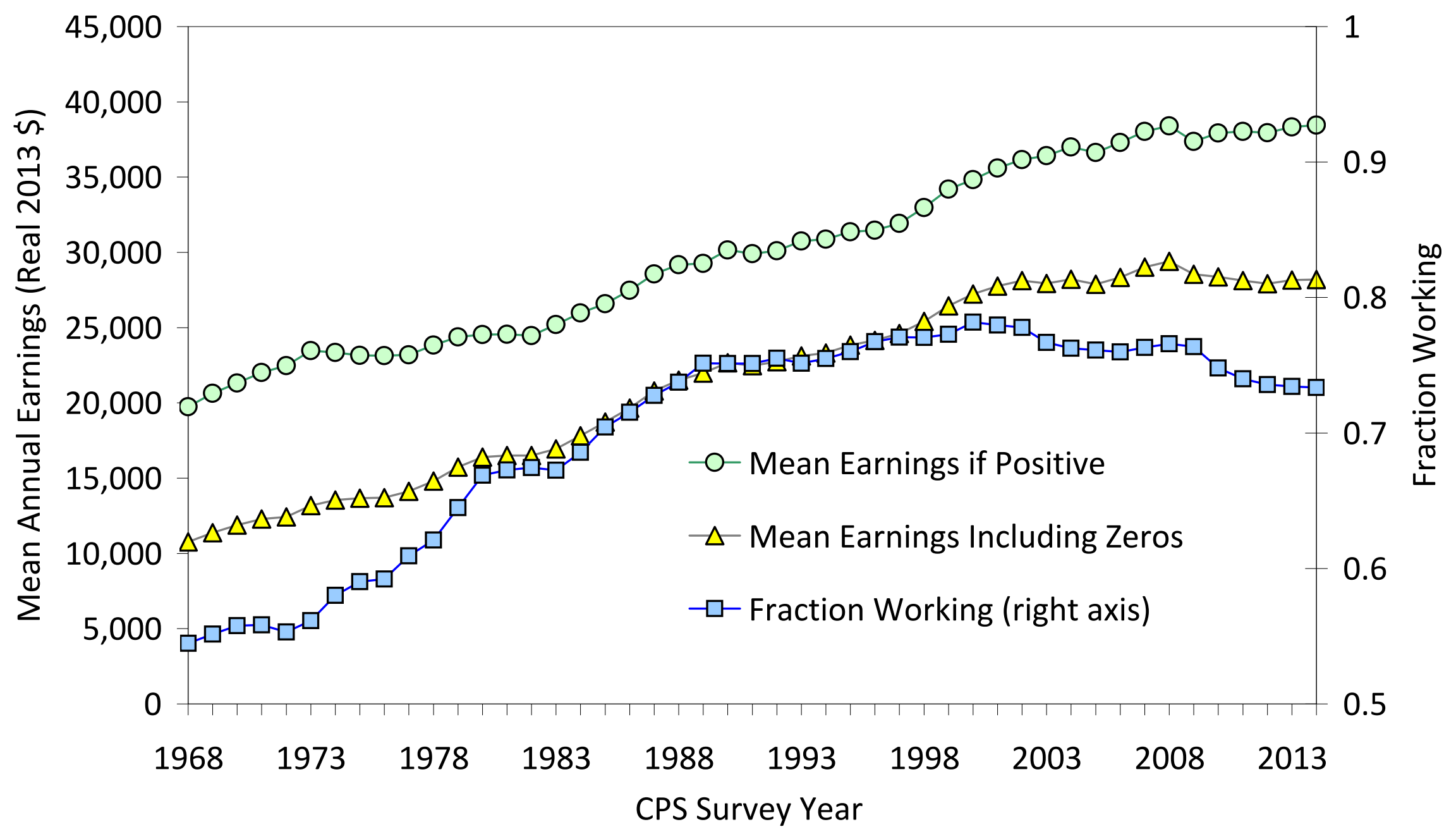

Note: sample restricted to females age 24-60 in all years. Sample weights are not used. Earnings are censored at 5th and 99th percentiles, with no adjustment for topcoding. 
Figure 3: Trends in Female Earnings Inequality - Annual Data from March CPS

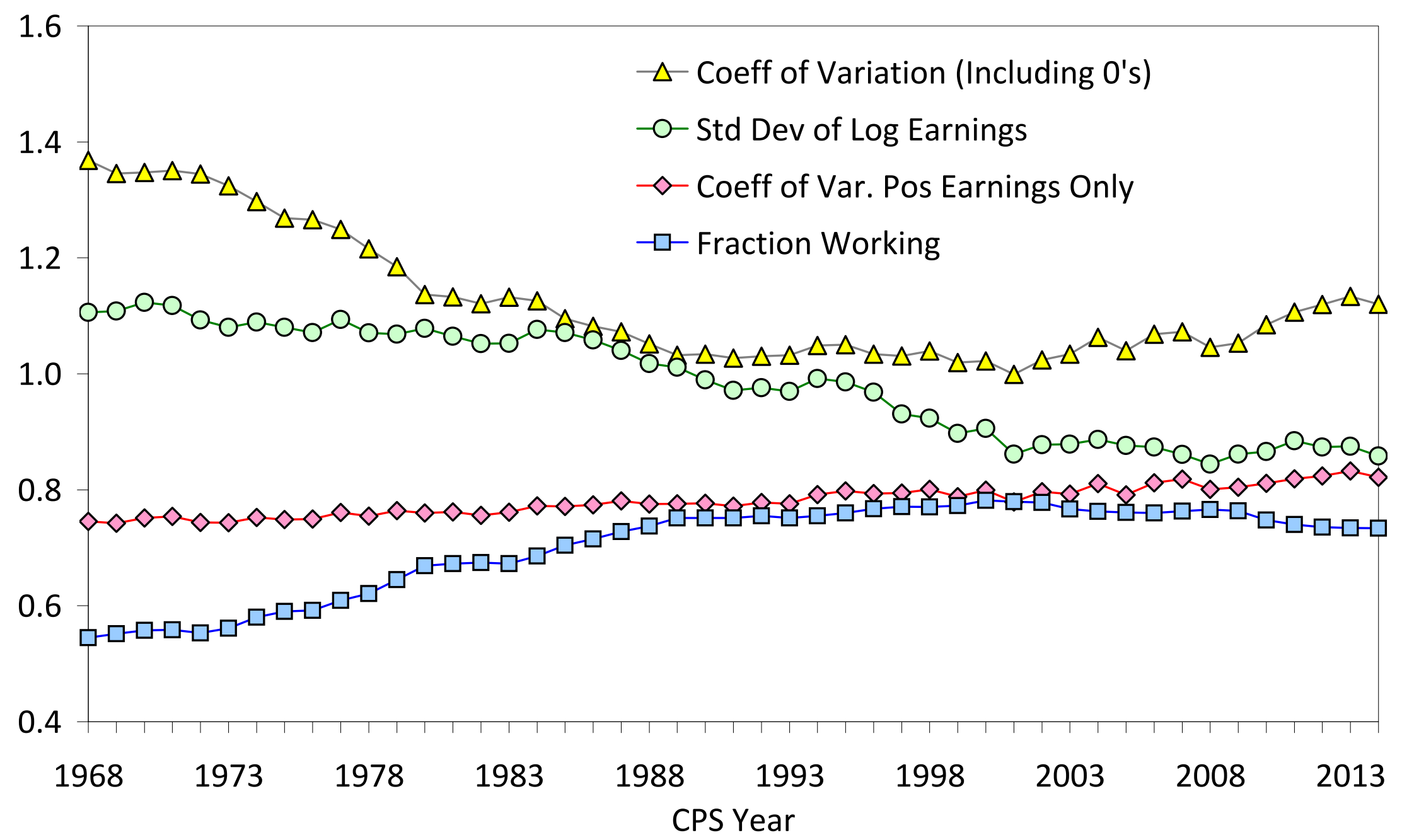

Note: sample restricted to females age 24-60 in all years. Earnings in real 2013 dollars are censored at 5th and 99th percentiles with no adjustment for topcoding. 


\section{Figure 4: Comparisons of PSID Panels and CPS}

a: Fraction of Females Working During Year - PSID vs. CPS

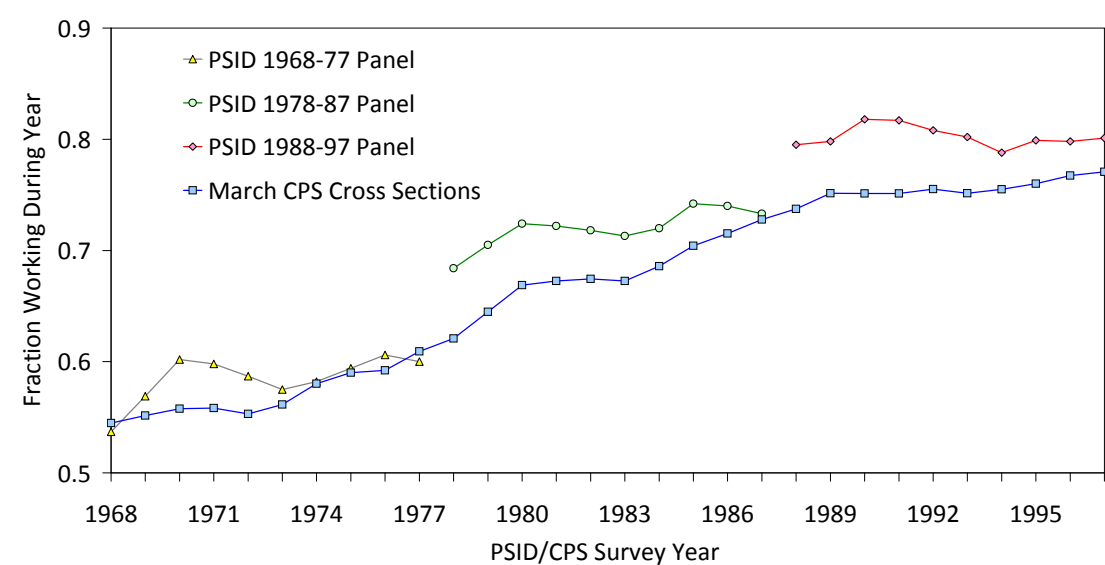

c: Coefficient of Variation of Female Earnings - PSID vs. CPS

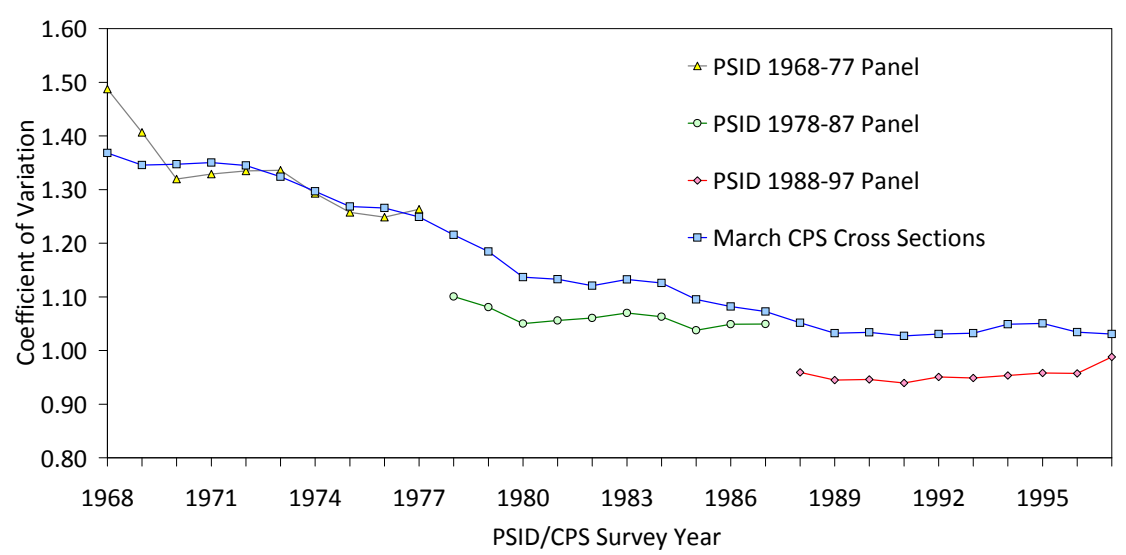

b: Mean Earnings Conditional on Working - PSID vs. CPS

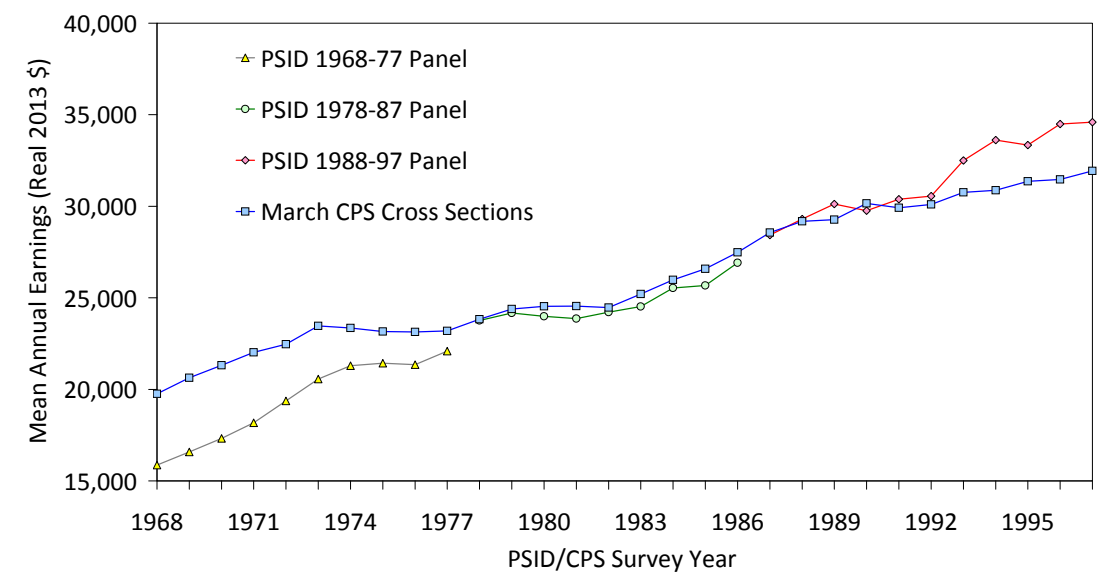

d: Standard Deviation of Log Earnings - PSID vs. CPS

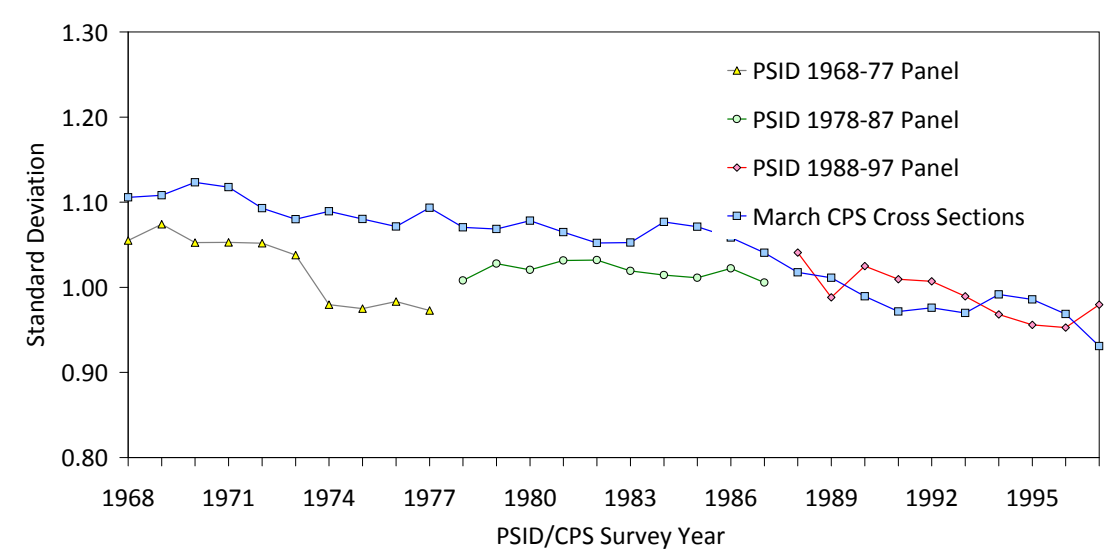


Figure 5: Measures of Year-to-Year Volatility in Earnings

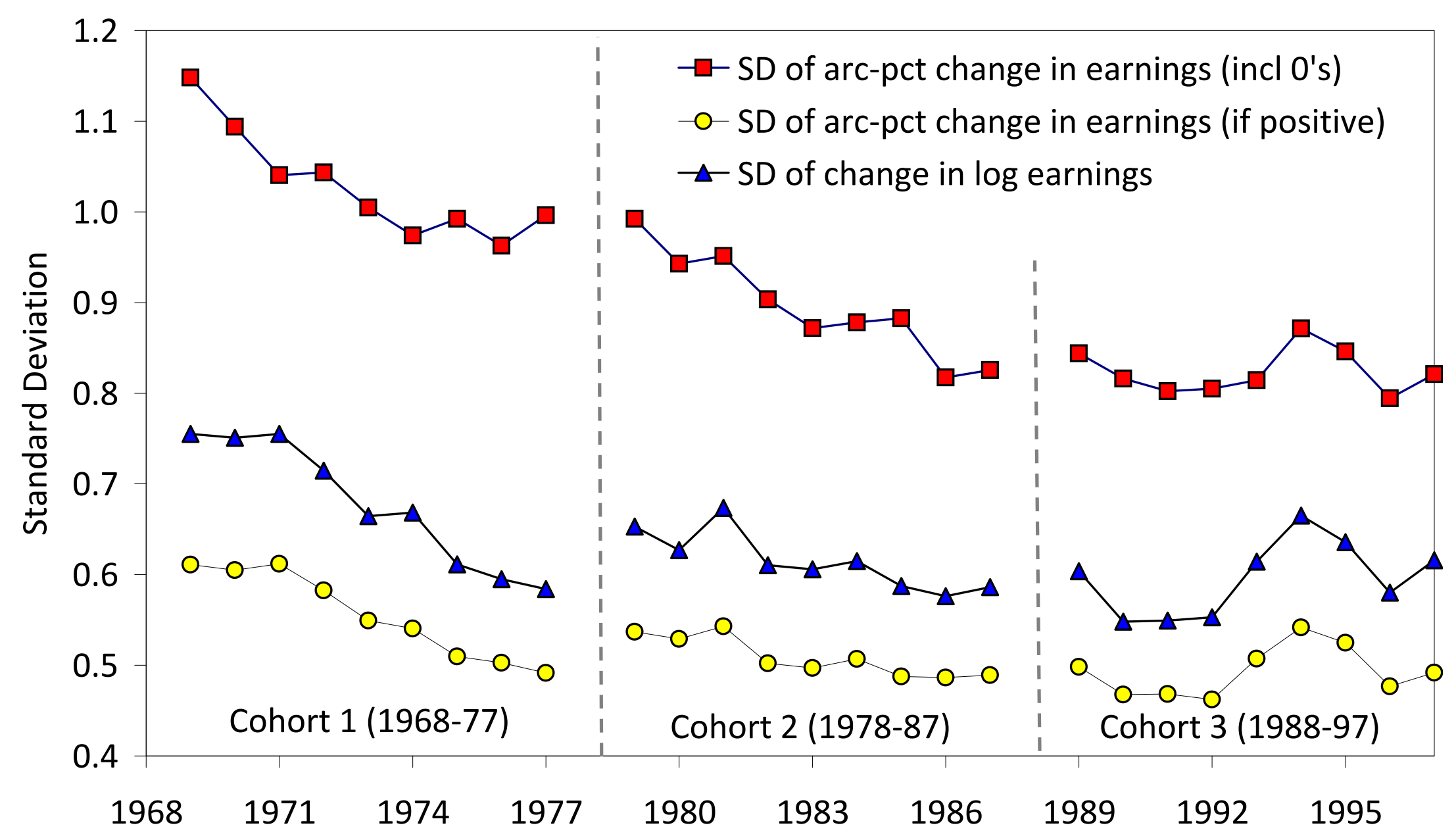

Note: see note to Figure 4. 
Figure 6: Changes in Components of Earnings Inequality for Female Heads

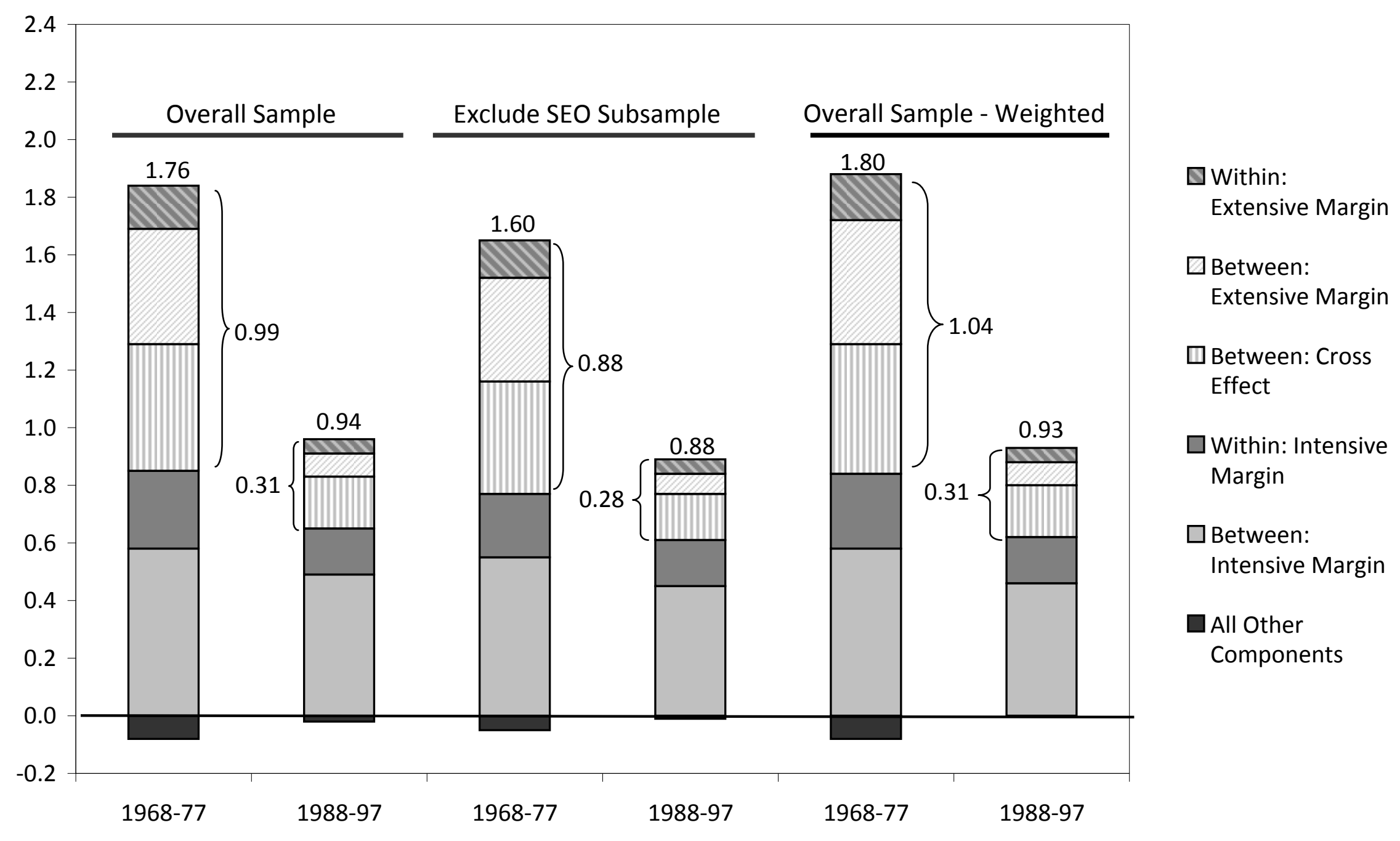


Figure 7: Comparisons of Actual and Predicted Outcomes

\section{a: Actual and Predicted Employment Rates}

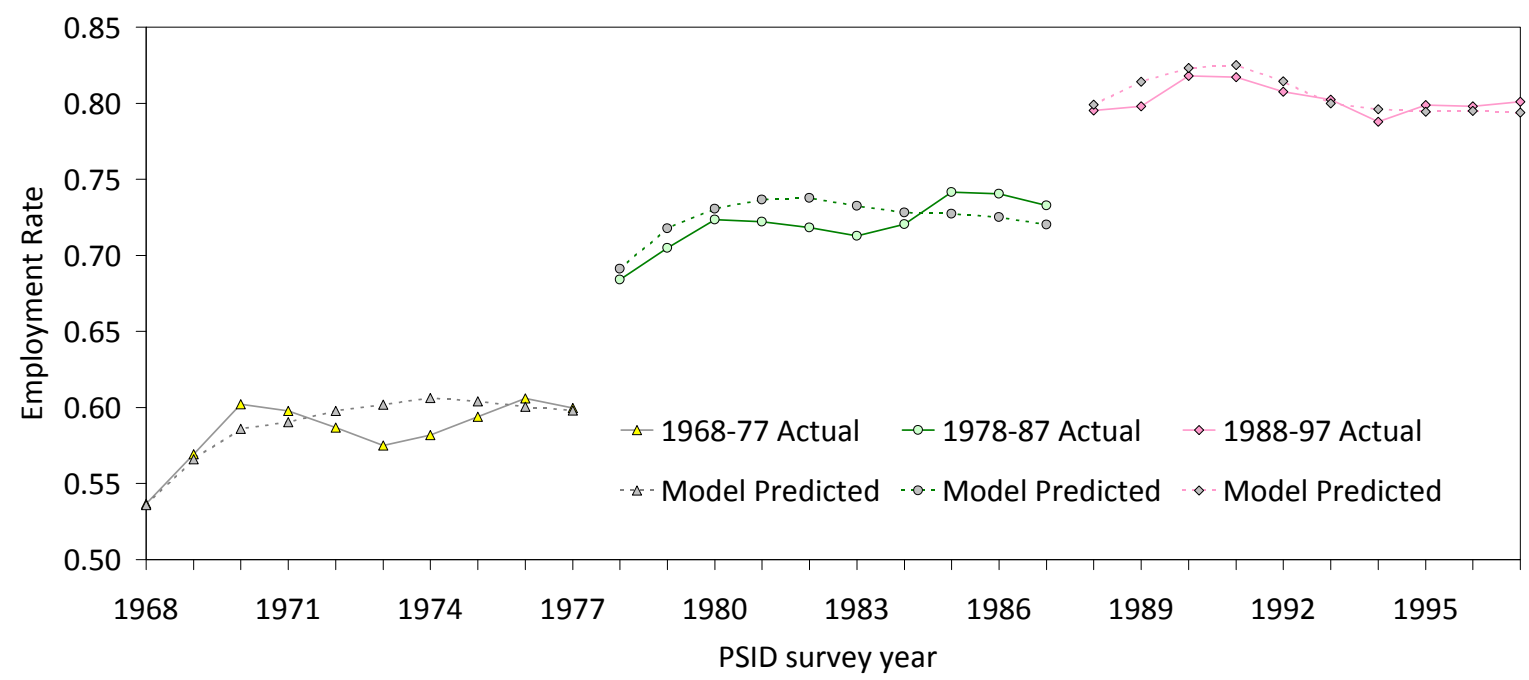

b: Actual and Predicted Mean Log Earnings

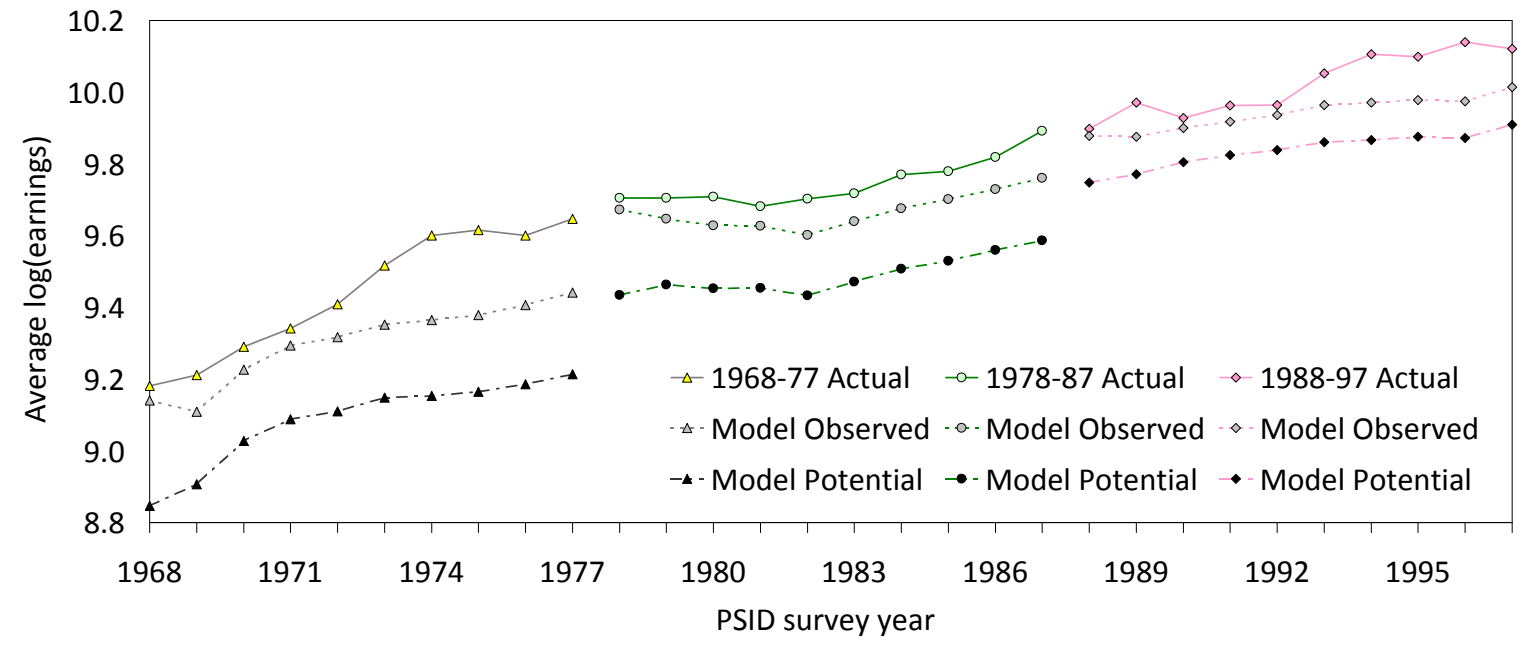

c: Actual and Predicted Coefficient of Variation of Earnings

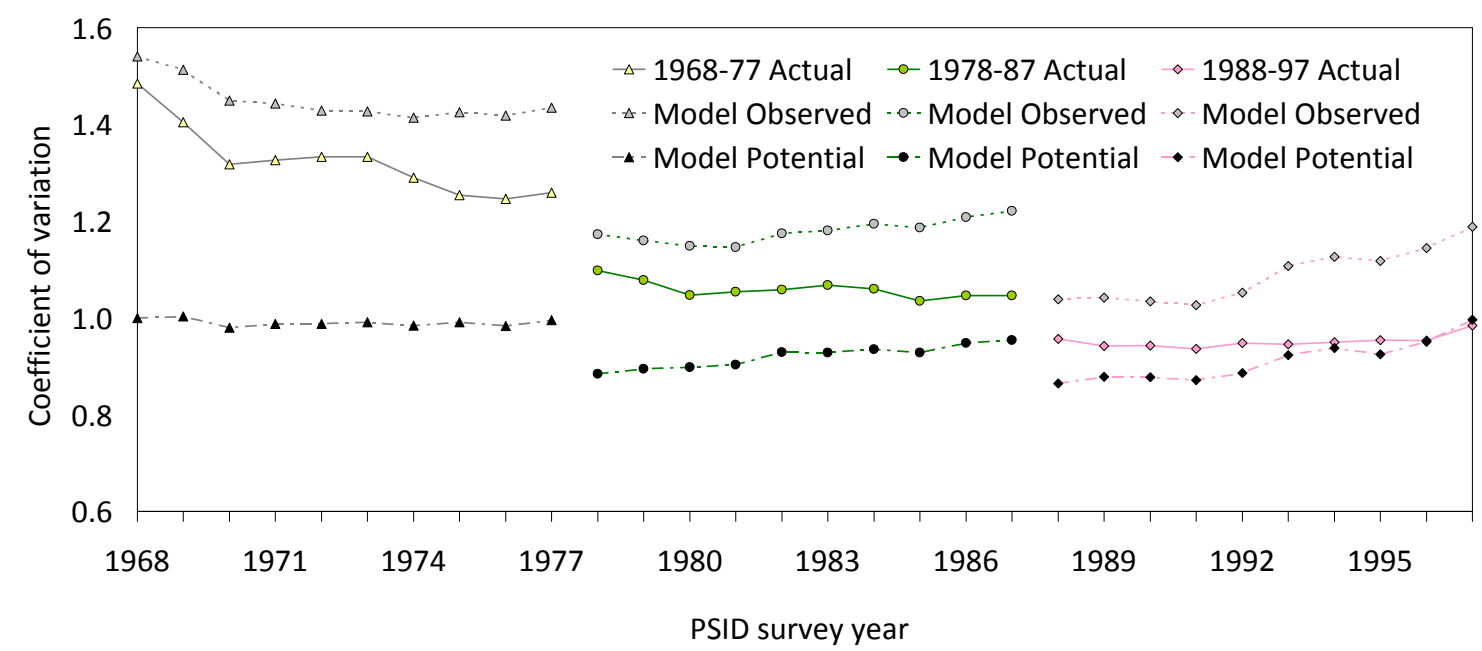


Table 1: Characteristics of Female Heads in Three 10-year Panels of PSID

\begin{tabular}{|c|c|c|c|c|c|c|c|c|c|}
\hline & \multicolumn{3}{|c|}{$1968-77$} & \multicolumn{3}{|c|}{$1978-87$} & \multicolumn{3}{|c|}{$1988-97$} \\
\hline & All & Not Emp. & Employed & All & Not Emp. & Employed & All & Not Emp. & Employed \\
\hline$\overline{\text { Age }}$ & 41.6 & 41.5 & 41.6 & 39.8 & 40.8 & 39.4 & 39.2 & 39.7 & 39.0 \\
\hline Education & 11.2 & 10.8 & 11.5 & 12.6 & 11.7 & 12.9 & 13.2 & 12.4 & 13.4 \\
\hline Black & 0.37 & 0.35 & 0.38 & 0.33 & 0.35 & 0.33 & 0.31 & 0.37 & 0.29 \\
\hline Partner present & 0.71 & 0.78 & 0.66 & 0.71 & 0.76 & 0.69 & 0.74 & 0.76 & 0.74 \\
\hline Always with partner & 0.59 & 0.68 & 0.54 & 0.60 & 0.66 & 0.58 & 0.63 & 0.67 & 0.62 \\
\hline Never with partner & 0.20 & 0.16 & 0.22 & 0.19 & 0.18 & 0.20 & 0.16 & 0.17 & 0.16 \\
\hline Any kids present & 0.75 & 0.81 & 0.71 & 0.68 & 0.74 & 0.66 & 0.68 & 0.74 & 0.67 \\
\hline Number kids present & 2.14 & 2.48 & 1.90 & 1.44 & 1.72 & 1.34 & 1.41 & 1.77 & 1.33 \\
\hline Kid under 6 present & 0.27 & 0.35 & 0.22 & 0.27 & 0.35 & 0.24 & 0.29 & 0.40 & 0.26 \\
\hline Kid 6-17 present & 0.48 & 0.45 & 0.49 & 0.41 & 0.39 & 0.43 & 0.39 & 0.33 & 0.41 \\
\hline Ever have kids present & 0.88 & 0.91 & 0.85 & 0.85 & 0.88 & 0.84 & 0.82 & 0.86 & 0.81 \\
\hline Always have kids present & 0.59 & 0.66 & 0.54 & 0.47 & 0.53 & 0.45 & 0.50 & 0.57 & 0.49 \\
\hline \multicolumn{10}{|l|}{ Own employment outcomes: } \\
\hline Fraction years employed & 0.58 & 0.23 & 0.84 & 0.72 & 0.29 & 0.89 & 0.80 & 0.34 & 0.92 \\
\hline Always employed & 0.29 & 0.00 & 0.50 & 0.45 & 0.00 & 0.63 & 0.55 & 0.00 & 0.68 \\
\hline Never employed & 0.15 & 0.36 & 0.00 & 0.08 & 0.30 & 0.00 & 0.05 & 0.25 & 0.00 \\
\hline$P\left[E_{t}=1 \mid E_{t-1}=0, E_{t-2}=0\right]$ & 0.13 & -- & -- & 0.16 & -- & -- & 0.17 & -- & -- \\
\hline$P\left[E_{t}=1 \mid E_{t-1}=1, E_{t-2}=0\right]$ & 0.70 & -- & -- & 0.73 & -- & -- & 0.75 & -- & -- \\
\hline$P\left[E_{t}=1 \mid E_{t-1}=0, E_{t-2}=1\right]$ & 0.34 & -- & -- & 0.39 & -- & -- & 0.48 & -- & -- \\
\hline$P\left[E_{t}=1 \mid E_{t-1}=1, E_{t-2}=1\right]$ & 0.92 & -- & -- & 0.95 & -- & -- & 0.95 & -- & -- \\
\hline Earnings (including 0's) & 11,360 & 0 & 19,422 & 18,095 & 0 & 25,129 & 25,587 & 0 & 31,889 \\
\hline Avg. earnings all years & 11,360 & 2,598 & 17,578 & 18,095 & 3,747 & 23,672 & 25,587 & 5,873 & 30,443 \\
\hline \multicolumn{10}{|c|}{ Partner employment outcomes (in years partner present): } \\
\hline Partner age & 44.5 & 44.7 & 44.4 & 42.3 & 43.5 & 41.8 & 41.7 & 43.1 & 41.4 \\
\hline Partner employed & 0.94 & 0.93 & 0.95 & 0.93 & 0.88 & 0.95 & 0.94 & 0.89 & 0.95 \\
\hline Partner hours this year & 2,245 & 2,287 & 2,210 & 2,185 & 2,212 & 2,174 & 2,257 & 2,296 & 2,248 \\
\hline Partner earnings this year & 53,224 & 55,357 & 51,451 & 58,948 & 61,938 & 57,741 & 65,131 & 71,310 & 63,632 \\
\hline Mean partner earnings & 51,268 & 53,312 & 49,701 & 56,906 & 58,793 & 56,170 & 62,416 & 67,710 & 61,171 \\
\hline Number person-year obs. & 20,760 & 8,617 & 12,143 & 25,000 & 6,998 & 18,002 & 22,860 & 4,518 & 18,342 \\
\hline
\end{tabular}

Notes: Each cohort sample consists of balanced 10-year panel. Earnings measures are censored annually at the 5th and 99th percentiles, and adjusted to real 2013 dollars using the CPI-U index. Employed and not-employed subgroups are based on employment status in current year. $\mathrm{P}\left[\mathrm{E}_{\mathrm{t}}=1 \mid \mathrm{E}_{\mathrm{t}-1}=0, \mathrm{E}_{\mathrm{t}-2}=0\right]$ represents probability of employment in year $\mathrm{t}$ conditional on not being employed in year $\mathrm{t}-1$ or year $\mathrm{t}-2$. 
Table 2: Decomposition of Total Earnings Inequality into Within/Between Person and Extensive/Intensive Margins

\begin{tabular}{|c|c|c|c|c|c|c|}
\hline & \multicolumn{3}{|c|}{ Female Heads: } & \multicolumn{3}{|c|}{ Male Heads: } \\
\hline & 1968-1977 & 1978-1987 & 1988-1997 & 1968-1977 & 1978-1987 & 1988-1997 \\
\hline Total $\mathrm{CV}^{2}$ of annual earnings & 1.76 & 1.12 & 0.90 & 0.37 & 0.41 & 0.51 \\
\hline Within-person component & 0.46 & 0.24 & 0.21 & 0.07 & 0.10 & 0.12 \\
\hline (share of total) & $(0.26)$ & $(0.22)$ & $(0.23)$ & $(0.20)$ & $(0.23)$ & $(0.23)$ \\
\hline Wtd. avg of $\mathrm{CV}_{\mathrm{i}}^{2}$ (approx. within) & 0.42 & 0.24 & 0.21 & 0.07 & 0.10 & 0.12 \\
\hline Between-person component & 1.44 & 0.91 & 0.71 & 0.31 & 0.32 & 0.39 \\
\hline (share of total) & $(0.82)$ & $(0.81)$ & $(0.79)$ & $(0.82)$ & $(0.77)$ & $(0.77)$ \\
\hline Cross-term & -0.15 & -0.03 & -0.02 & -0.01 & 0.00 & -0.01 \\
\hline \multicolumn{7}{|c|}{ Decomposition of within-person component: } \\
\hline Extensive margin component & 0.15 & 0.07 & 0.05 & 0.01 & 0.01 & 0.02 \\
\hline (share of total) & $(0.09)$ & $(0.06)$ & $(0.06)$ & $(0.03)$ & $(0.02)$ & $(0.04)$ \\
\hline Intensive margin component & 0.27 & 0.17 & 0.16 & 0.06 & 0.08 & 0.10 \\
\hline (share of total) & $(0.15)$ & $(0.15)$ & $(0.18)$ & $(0.16)$ & (0.19) & $(0.20)$ \\
\hline \multicolumn{7}{|c|}{ Decomposition of between-person component: } \\
\hline Extensive margin component & 0.40 & 0.15 & 0.08 & 0.01 & 0.01 & 0.01 \\
\hline (share of total) & $(0.23)$ & $(0.13)$ & $(0.09)$ & $(0.02)$ & $(0.02)$ & $(0.02)$ \\
\hline Intensive margin component & 0.58 & 0.49 & 0.45 & 0.27 & 0.28 & 0.35 \\
\hline (share of total) & $(0.33)$ & $(0.43)$ & $(0.50)$ & $(0.73)$ & $(0.68)$ & $(0.68)$ \\
\hline Cross-term & 0.44 & 0.26 & 0.18 & 0.03 & 0.03 & 0.04 \\
\hline (share of total) & $(0.25)$ & $(0.23)$ & $(0.20)$ & $(0.07)$ & $(0.07)$ & $(0.08)$ \\
\hline Time variation & 0.02 & 0.01 & 0.00 & 0.00 & 0.00 & 0.00 \\
\hline
\end{tabular}

Notes: See text for details of decomposition. Samples are desribed in Table 1 (females) and Appendix Table 2 (males). 
Table 3: Female Intensive and Extensive Margin Model Estimates, by Cohort

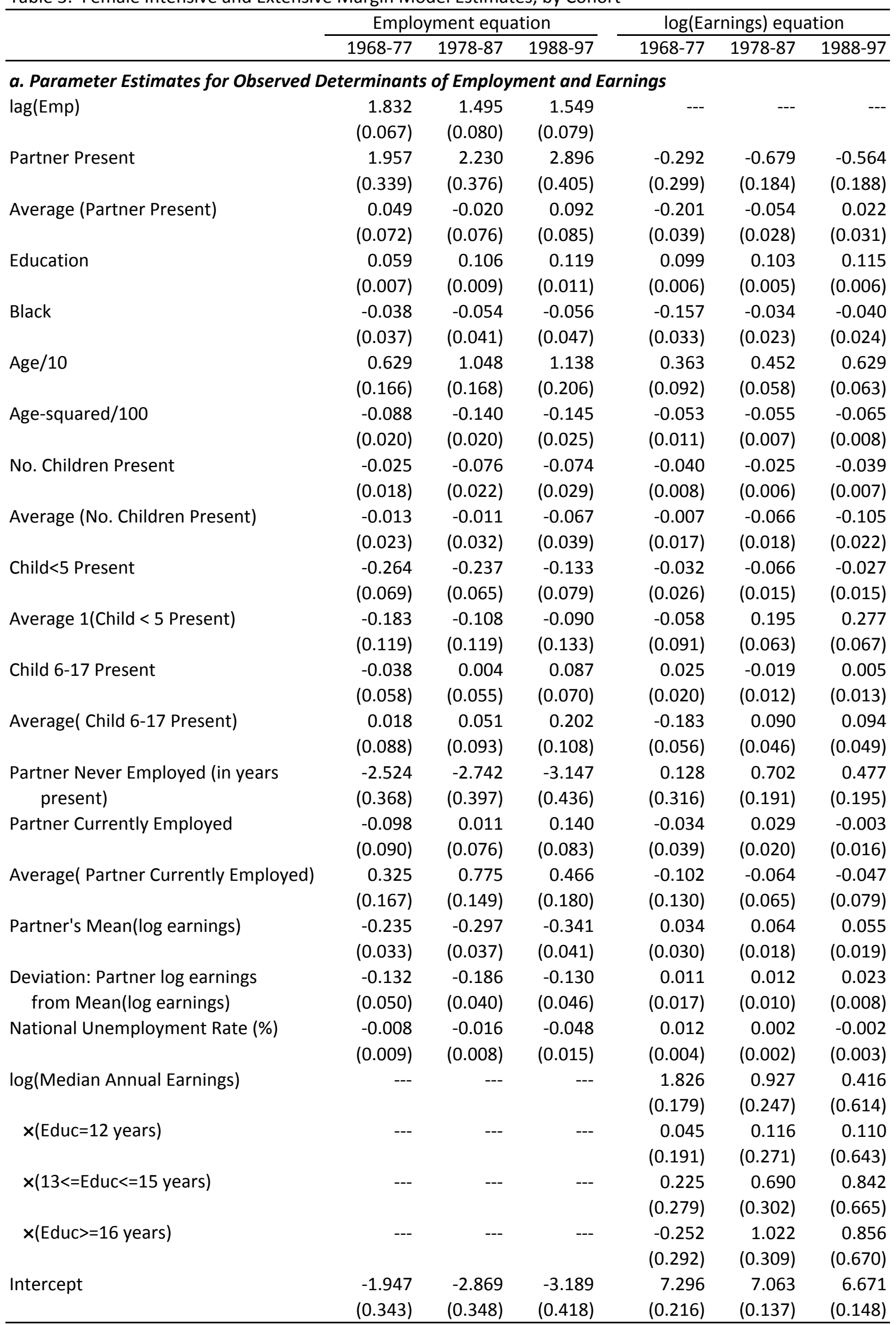

Notes: All models estimated using simulated MLE with 20 simulation replications. Standard errors in parentheses. Table continues. 
Table 3: Female Intensive and Extensive Margin Model Estimates, by Cohort (continued)

\begin{tabular}{|c|c|c|c|c|c|c|}
\hline & \multicolumn{3}{|c|}{ Employment equation } & \multicolumn{3}{|c|}{$\log$ (Earnings) equation } \\
\hline & 1968-77 & $1978-87$ & $1988-97$ & 1968-77 & $1978-87$ & $1988-97$ \\
\hline \multicolumn{7}{|l|}{ b. Error components } \\
\hline Var(Initial Permanent Component) & $\begin{array}{r}0.092 \\
(0.023)\end{array}$ & $\begin{array}{r}0.211 \\
(0.032)\end{array}$ & $\begin{array}{r}0.172 \\
(0.031)\end{array}$ & $\begin{array}{r}0.462 \\
(0.064)\end{array}$ & $\begin{array}{r}0.838 \\
(0.065)\end{array}$ & $\begin{array}{r}0.717 \\
(0.071)\end{array}$ \\
\hline $\operatorname{Var}($ Age-component) $* 10$ & $\begin{array}{r}0.095 \\
(0.012)\end{array}$ & $\begin{array}{r}0.101 \\
(0.012)\end{array}$ & $\begin{array}{r}0.132 \\
(0.015)\end{array}$ & $\begin{array}{r}0.280 \\
(0.055)\end{array}$ & $\begin{array}{r}0.251 \\
(0.055)\end{array}$ & $\begin{array}{r}0.439 \\
(0.074)\end{array}$ \\
\hline Var(Permanent shock) & $\begin{array}{r}0.025 \\
(0.005)\end{array}$ & $\begin{array}{r}0.042 \\
(0.007)\end{array}$ & $\begin{array}{r}0.051 \\
(0.008)\end{array}$ & $\begin{array}{r}0.065 \\
(0.006)\end{array}$ & $\begin{array}{r}0.092 \\
(0.005)\end{array}$ & $\begin{array}{r}0.087 \\
(0.005)\end{array}$ \\
\hline $\operatorname{Var}(\mathrm{MA}(1)$ component) & --- & --- & --- & $\begin{array}{r}0.491 \\
(0.014)\end{array}$ & $\begin{array}{r}0.359 \\
(0.010)\end{array}$ & $\begin{array}{r}0.341 \\
(0.009)\end{array}$ \\
\hline MA(1) Correlation & $\begin{array}{r}-0.514 \\
(0.040)\end{array}$ & $\begin{array}{l}-0.394 \\
(0.041)\end{array}$ & $\begin{array}{l}-0.609 \\
(0.085)\end{array}$ & $\begin{array}{r}0.261 \\
(0.016)\end{array}$ & $\begin{array}{r}0.253 \\
(0.015)\end{array}$ & $\begin{array}{r}0.230 \\
(0.014)\end{array}$ \\
\hline \multicolumn{7}{|l|}{ Type-2 distribution } \\
\hline Mean-shift & --- & --- & --- & $\begin{array}{r}1.078 \\
(0.033)\end{array}$ & $\begin{array}{r}1.040 \\
(0.030)\end{array}$ & $\begin{array}{r}0.898 \\
(0.034)\end{array}$ \\
\hline Variance-scale & --- & --- & --- & $\begin{array}{r}0.719 \\
(0.013)\end{array}$ & $\begin{array}{r}0.692 \\
(0.010)\end{array}$ & $\begin{array}{r}0.634 \\
(0.011)\end{array}$ \\
\hline Probability of Type 2 & --- & --- & --- & $\begin{array}{r}0.102 \\
(0.004)\end{array}$ & $\begin{array}{r}0.064 \\
(0.002)\end{array}$ & $\begin{array}{r}0.067 \\
(0.002)\end{array}$ \\
\hline \multicolumn{7}{|c|}{ Correlation (Extensive \& Intensive error components) } \\
\hline Initial Permanent Components & --- & --- & --- & $\begin{array}{r}0.689 \\
(0.035)\end{array}$ & $\begin{array}{r}0.658 \\
(0.029)\end{array}$ & $\begin{array}{r}0.563 \\
(0.033)\end{array}$ \\
\hline Permanent shocks & --- & --- & --- & $\begin{array}{r}0.324 \\
(0.055)\end{array}$ & $\begin{array}{r}0.201 \\
(0.034)\end{array}$ & $\begin{array}{r}0.128 \\
(0.034)\end{array}$ \\
\hline MA(1) shocks & --- & --- & --- & $\begin{array}{l}-0.370 \\
(0.025)\end{array}$ & $\begin{array}{r}-0.256 \\
(0.026)\end{array}$ & $\begin{array}{c}-0.212 \\
(0.025)\end{array}$ \\
\hline log Likelihood & --- & --- & --- & $-18,870.9$ & $-21,412.1$ & $-18,526.8$ \\
\hline No. Observations & & & & 20,760 & 25,000 & 22,860 \\
\hline
\end{tabular}

Notes: All models estimated using Simulated MLE with 20 simulation replications. Standard errors in parentheses. Initial conditions models reported in Appendix. 
Table 4: Actual and Predicted Components of Total Earnings Inequality of Females in PSID

\begin{tabular}{|c|c|c|c|c|c|c|c|c|}
\hline & \multicolumn{2}{|c|}{$1968-77$} & \multicolumn{2}{|c|}{$1978-87$} & \multicolumn{2}{|c|}{$1988-97$} & \multicolumn{2}{|c|}{$\begin{array}{c}\text { Change: } 1968-77 \text { to } \\
1988-97\end{array}$} \\
\hline & Actual & Simulated & Actual & Simulated & Actual & Simulated & Actual & Simulated \\
\hline Mean employment rate & 0.58 & 0.59 & 0.72 & 0.72 & 0.80 & 0.81 & 0.22 & 0.22 \\
\hline Total $\mathrm{CV}^{2}$ of ann. earns & 1.76 & 2.10 & 1.12 & 1.39 & 0.90 & 1.19 & -0.85 & -0.92 \\
\hline Within-person comp. & 0.46 & 0.79 & 0.24 & 0.42 & 0.21 & 0.34 & -0.26 & -0.44 \\
\hline Wtd Avg. of $\mathrm{CV}_{\mathrm{i}}^{2}$ & 0.42 & 0.75 & 0.24 & 0.42 & 0.21 & 0.34 & -0.21 & -0.40 \\
\hline Between-person comp. & 1.44 & 1.53 & 0.91 & 1.02 & 0.71 & 0.89 & -0.73 & -0.64 \\
\hline Cross-term & -0.15 & -0.22 & -0.03 & -0.05 & -0.02 & -0.05 & 0.13 & 0.17 \\
\hline \multicolumn{9}{|c|}{ Decompostion of within-person component } \\
\hline Exten. margin comp. & 0.15 & 0.23 & 0.07 & 0.12 & 0.05 & 0.08 & -0.10 & -0.15 \\
\hline Inten. margin comp. & 0.27 & 0.51 & 0.17 & 0.30 & 0.16 & 0.26 & -0.11 & -0.25 \\
\hline \multicolumn{9}{|c|}{ Decompostion of between-person component } \\
\hline Exten. margin comp. & 0.40 & 0.42 & 0.15 & 0.17 & 0.08 & 0.09 & -0.33 & -0.32 \\
\hline Inten. margin comp. & 0.58 & 0.64 & 0.49 & 0.56 & 0.45 & 0.58 & -0.12 & -0.06 \\
\hline Cross term & 0.44 & 0.45 & 0.26 & 0.28 & 0.18 & 0.21 & -0.26 & -0.24 \\
\hline Time-variation & 0.02 & 0.03 & 0.01 & 0.01 & 0.00 & 0.01 & -0.02 & -0.02 \\
\hline
\end{tabular}

Note: see notes in Table 2. Simulated entries are based on estimated model presented in Table 3. 
Table 5a: Actual and Simulated Changes in Inequality Between 1968-77 and 1988-97 Cohorts

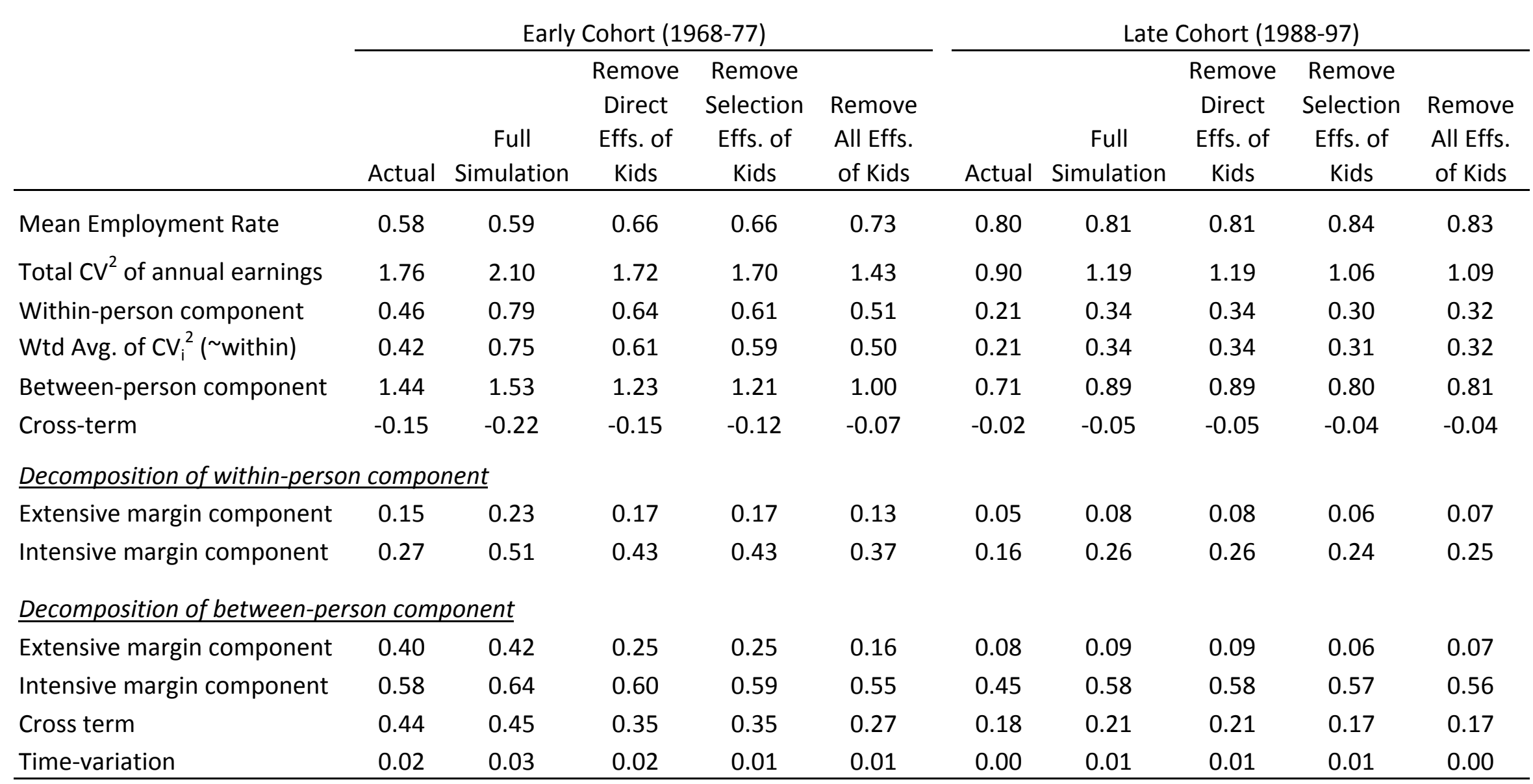

Notes: see text for description of alternative simulations. 


\begin{tabular}{|c|c|c|c|c|c|c|}
\hline & \multicolumn{5}{|c|}{ Simulated Changes, $1968-77$ (Early) to $1987-97$ (Late) Cohort } & \multirow{2}{*}{$\begin{array}{c}\text { Share of Change } \\
\text { Attributable to } \\
\text { Changing Effect of } \\
\text { Kids } \\
\end{array}$} \\
\hline & Actual & Full Simulation & $\begin{array}{c}\text { Remove Direct } \\
\text { Effs. of Kids }\end{array}$ & $\begin{array}{c}\text { Remove } \\
\text { Selection Effs. } \\
\text { of Kids } \\
\end{array}$ & $\begin{array}{l}\text { Remove All } \\
\text { Effs. of Kids }\end{array}$ & \\
\hline Mean Employment Rate & 0.22 & 0.22 & 0.14 & 0.18 & 0.11 & 0.50 \\
\hline Total $\mathrm{CV}^{2}$ of annual earnings & -0.85 & -0.92 & -0.53 & -0.63 & -0.34 & 0.63 \\
\hline Within-person component & -0.26 & -0.44 & -0.29 & -0.30 & -0.19 & 0.57 \\
\hline Wtd Avg. of $\mathrm{CV}_{i}^{2}$ (approx. within) & -0.21 & -0.40 & -0.26 & -0.29 & -0.18 & 0.56 \\
\hline Between-person component & -0.73 & -0.64 & -0.34 & -0.41 & -0.19 & 0.71 \\
\hline Cross-term & 0.13 & 0.17 & 0.10 & 0.07 & 0.03 & 0.79 \\
\hline \multicolumn{7}{|c|}{ Decomposition of within-person component } \\
\hline Extensive margin component & -0.10 & -0.15 & -0.09 & -0.10 & -0.06 & 0.63 \\
\hline Intensive margin component & -0.11 & -0.25 & -0.17 & -0.18 & -0.12 & 0.51 \\
\hline \multicolumn{7}{|c|}{ Decomposition of between-person component } \\
\hline Extensive margin component & -0.33 & -0.32 & -0.16 & -0.19 & -0.09 & 0.72 \\
\hline Intensive margin component & -0.12 & -0.06 & -0.02 & -0.02 & 0.01 & 1.12 \\
\hline Cross term & -0.26 & -0.24 & -0.14 & -0.19 & -0.10 & 0.58 \\
\hline Time-variation & -0.02 & -0.02 & -0.02 & -0.01 & -0.01 & 0.78 \\
\hline
\end{tabular}

Notes: Entries are changes between 1968-77 cohort and 1988-97 cohort. 
Table 6: Actual and Simulated Components of Earnings Inequality, Early to Late Cohort

\begin{tabular}{|c|c|c|c|c|c|c|c|c|c|c|}
\hline & \multicolumn{3}{|c|}{ Early Cohort (1968-77) } & \multicolumn{3}{|c|}{ Late Cohort (1988-97) } & \multicolumn{3}{|c|}{ Change from Early to Late Cohort } & \multirow[b]{2}{*}{$\begin{array}{c}\text { Share of Change } \\
\text { Attributable to } \\
\text { Changing Effs. of } \\
\text { Spouse }\end{array}$} \\
\hline & Actual & $\begin{array}{c}\text { Full } \\
\text { Simulation }\end{array}$ & $\begin{array}{c}\text { Remove } \\
\text { Effects of } \\
\text { Spouse }\end{array}$ & Actual & $\begin{array}{c}\text { Full } \\
\text { Simulation }\end{array}$ & $\begin{array}{c}\text { Remove } \\
\text { Effects of } \\
\text { Spouse }\end{array}$ & Actual & $\begin{array}{c}\text { Full } \\
\text { Simulation }\end{array}$ & $\begin{array}{c}\text { Remove } \\
\text { Effects of } \\
\text { Spouse }\end{array}$ & \\
\hline Mean Employment Rate & 0.58 & 0.59 & 0.71 & 0.80 & 0.81 & 0.84 & 0.22 & 0.22 & 0.13 & 0.40 \\
\hline Total $\mathrm{CV}^{2}$ of annual earnings & 1.76 & 2.10 & 1.48 & 0.90 & 1.19 & 1.10 & -0.85 & -0.92 & -0.38 & 0.59 \\
\hline Within-person component & 0.46 & 0.79 & 0.53 & 0.21 & 0.34 & 0.32 & -0.26 & -0.44 & -0.21 & 0.52 \\
\hline Wtd Avg. of $\mathrm{CV}_{\mathrm{i}}^{2}$ ( $\sim$ within) & 0.42 & 0.75 & 0.51 & 0.21 & 0.34 & 0.32 & -0.21 & -0.40 & -0.19 & 0.53 \\
\hline Between-person component & 1.44 & 1.53 & 1.08 & 0.71 & 0.89 & 0.83 & -0.73 & -0.64 & -0.24 & 0.62 \\
\hline Cross-term & -0.15 & -0.22 & -0.13 & -0.02 & -0.05 & -0.05 & 0.13 & 0.17 & 0.08 & 0.52 \\
\hline \multicolumn{11}{|c|}{ Decomposition of within-person component } \\
\hline Extensive margin component & 0.15 & 0.23 & 0.13 & 0.05 & 0.08 & 0.06 & -0.10 & -0.15 & -0.07 & 0.55 \\
\hline Intensive margin component & 0.27 & 0.51 & 0.38 & 0.16 & 0.26 & 0.26 & -0.11 & -0.25 & -0.12 & 0.52 \\
\hline \multicolumn{11}{|c|}{ Decomposition of between-person component } \\
\hline Extensive margin component & 0.40 & 0.42 & 0.18 & 0.08 & 0.09 & 0.06 & -0.33 & -0.32 & -0.12 & 0.63 \\
\hline Intensive margin component & 0.58 & 0.64 & 0.57 & 0.45 & 0.58 & 0.58 & -0.12 & -0.06 & 0.01 & 1.14 \\
\hline Cross term & 0.44 & 0.45 & 0.30 & 0.18 & 0.21 & 0.18 & -0.26 & -0.24 & -0.12 & 0.51 \\
\hline Time-variation & 0.02 & 0.03 & 0.02 & 0.00 & 0.01 & 0.01 & -0.02 & -0.02 & -0.01 & 0.39 \\
\hline
\end{tabular}

Note: see text for decription of alternative simulations. 
Table 7: Actual and Simulated Components of Earnings Inequality, Early to Late Cohort

\begin{tabular}{|c|c|c|c|c|c|c|c|c|c|c|}
\hline & \multicolumn{3}{|c|}{ Early Cohort (1968-77) } & \multicolumn{3}{|c|}{ Late Cohort (1988-97) } & \multicolumn{3}{|c|}{ Change: Early to Late Cohort } & \multirow{2}{*}{$\begin{array}{c}\text { Share of Change } \\
\text { Attributable to } \\
\text { Changing Effs. of } \\
\text { Spouse/Kids }\end{array}$} \\
\hline & Actual & Simulation & $\begin{array}{c}\text { Remove } \\
\text { Effects of } \\
\text { Spouses/Kids }\end{array}$ & Actual & Simulation & $\begin{array}{c}\text { Remove } \\
\text { Effects of } \\
\text { Spouses/Kids }\end{array}$ & Actual & Simulation & $\begin{array}{l}\text { Remove Effects } \\
\text { of } \\
\text { Spouses/Kids }\end{array}$ & \\
\hline Mean empl. rate & 0.58 & 0.59 & 0.82 & 0.80 & 0.81 & 0.89 & 0.22 & 0.22 & 0.07 & 0.69 \\
\hline Total $\mathrm{CV}^{2}$ of ann. earns & 1.76 & 2.10 & 1.07 & 0.90 & 1.19 & 0.95 & -0.85 & -0.92 & -0.12 & 0.87 \\
\hline Within-person comp. & 0.46 & 0.79 & 0.36 & 0.21 & 0.34 & 0.27 & -0.26 & -0.44 & -0.10 & 0.78 \\
\hline Wtd Avg. of $\mathrm{CV}_{i}^{2}$ ( $\sim$ within) & 0.42 & 0.75 & 0.36 & 0.21 & 0.34 & 0.27 & -0.21 & -0.40 & -0.09 & 0.78 \\
\hline Between-person comp. & 1.44 & 1.53 & 0.76 & 0.71 & 0.89 & 0.72 & -0.73 & -0.64 & -0.04 & 0.94 \\
\hline Cross-term & -0.15 & -0.22 & -0.05 & -0.02 & -0.05 & -0.04 & 0.13 & 0.17 & 0.02 & 0.90 \\
\hline \multicolumn{11}{|c|}{ Decomposition of within-person component } \\
\hline Exten. margin comp. & 0.15 & 0.23 & 0.07 & 0.05 & 0.08 & 0.04 & -0.10 & -0.15 & -0.03 & 0.82 \\
\hline Inten. margin comp. & 0.27 & 0.51 & 0.29 & 0.16 & 0.26 & 0.23 & -0.11 & -0.25 & -0.06 & 0.76 \\
\hline \multicolumn{11}{|c|}{ Decomposition of between-person component } \\
\hline Exten. margin comp. & 0.40 & 0.42 & 0.07 & 0.08 & 0.09 & 0.04 & -0.33 & -0.32 & -0.03 & 0.90 \\
\hline Inten. margin comp. & 0.58 & 0.64 & 0.51 & 0.45 & 0.58 & 0.55 & -0.12 & -0.06 & 0.05 & 1.83 \\
\hline Cross term & 0.44 & 0.45 & 0.18 & 0.18 & 0.21 & 0.13 & -0.26 & -0.24 & -0.05 & 0.79 \\
\hline Time-variation & 0.02 & 0.03 & 0.01 & 0.00 & 0.01 & 0.00 & -0.02 & -0.02 & 0.00 & 0.83 \\
\hline
\end{tabular}

Note: see text for decription of alternative simulations. 
Appendix Figure 1: Fraction of Females Married/with Partner

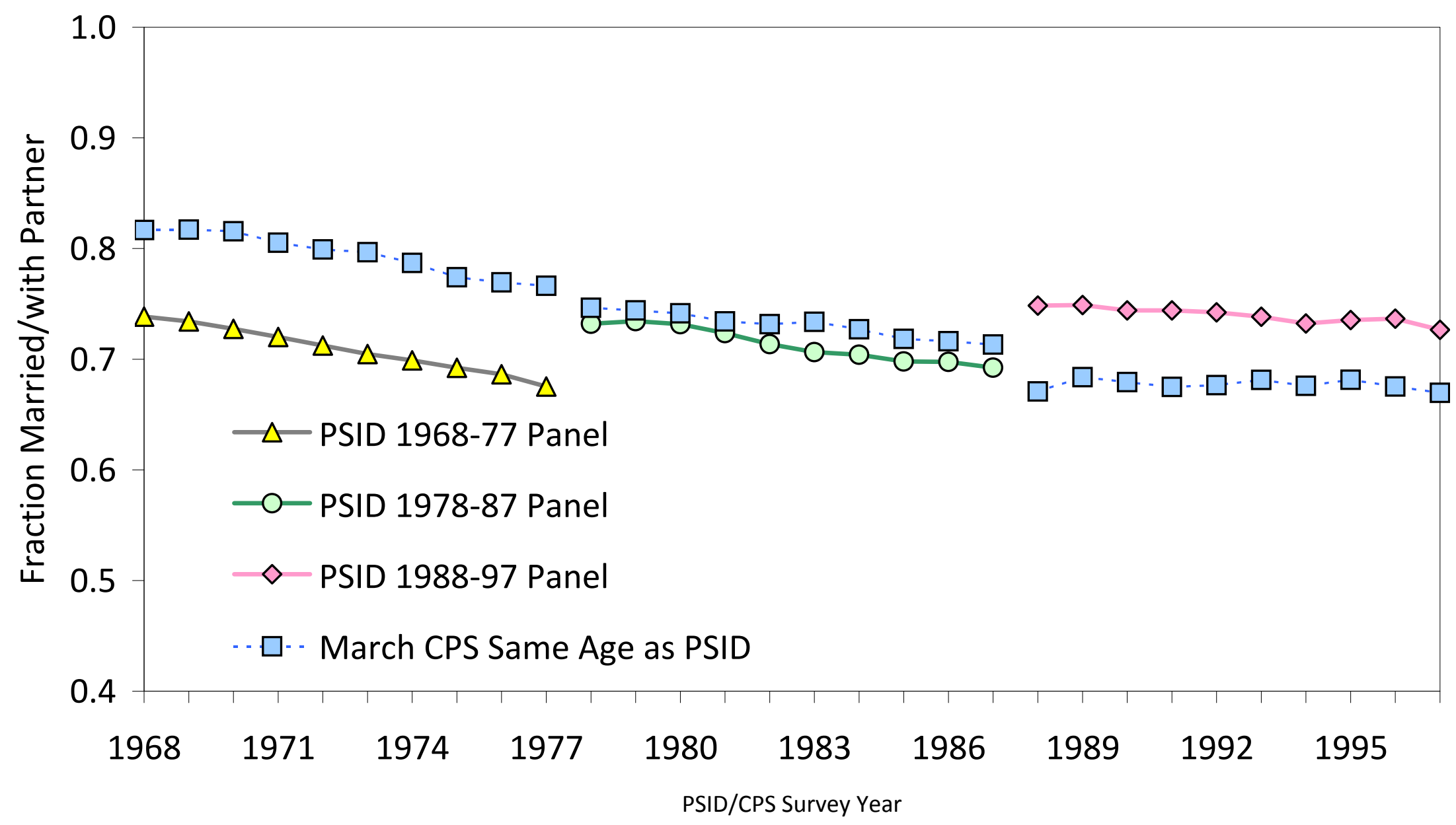

Note: PSID samples restricted to females age 24-60 in all years. March CPS samples have same age limits in survey year as corresponding PSID samples. 
Appendix Figure 2: Fraction of Females with Child Under 6

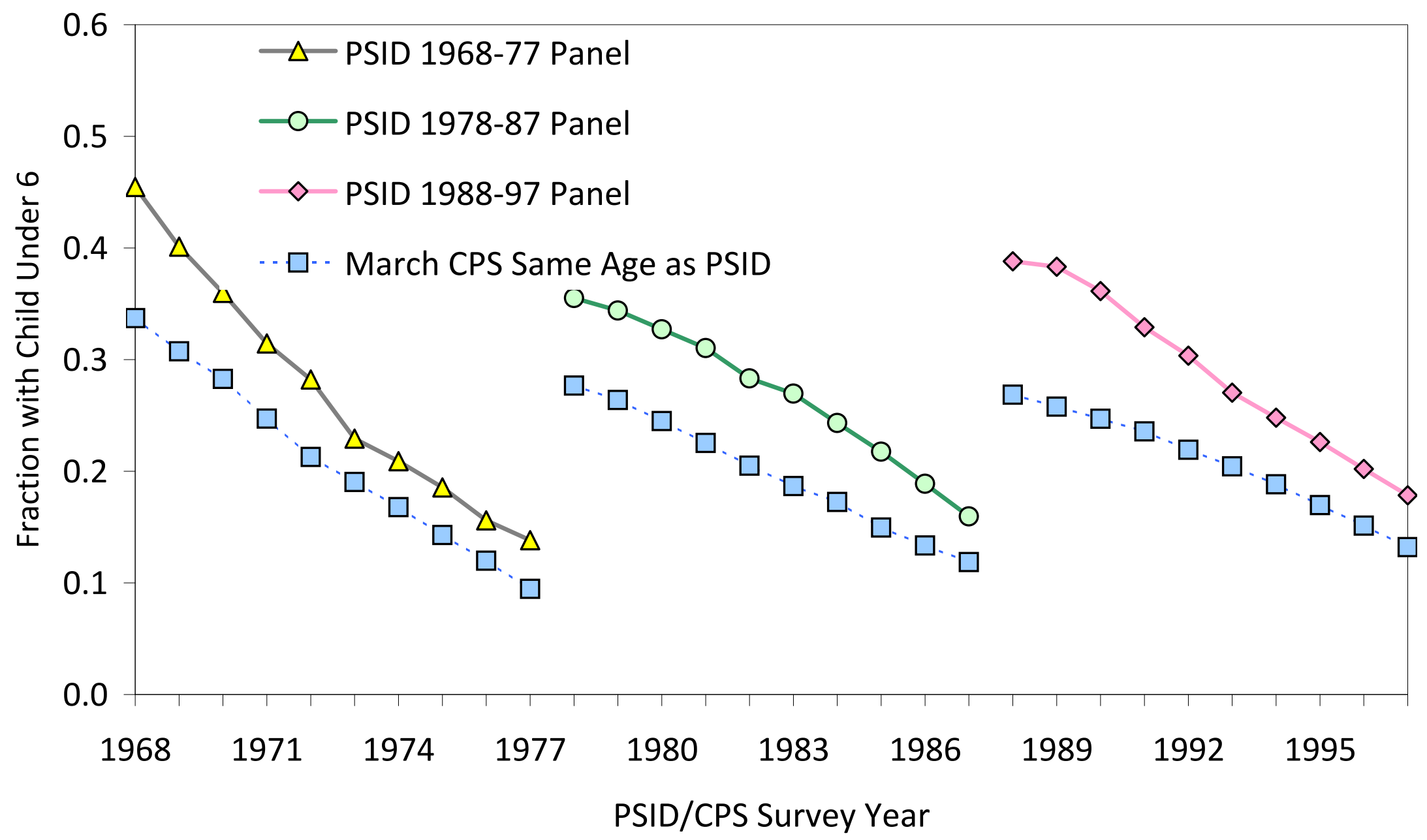

Note: PSID samples restricted to females age 24-60 in all years. March CPS samples have same age limits in survey year as corresponding PSID samples. 
Appendix Figure 3: Dynamic responses of Employment and log(earnings) to employment shocks

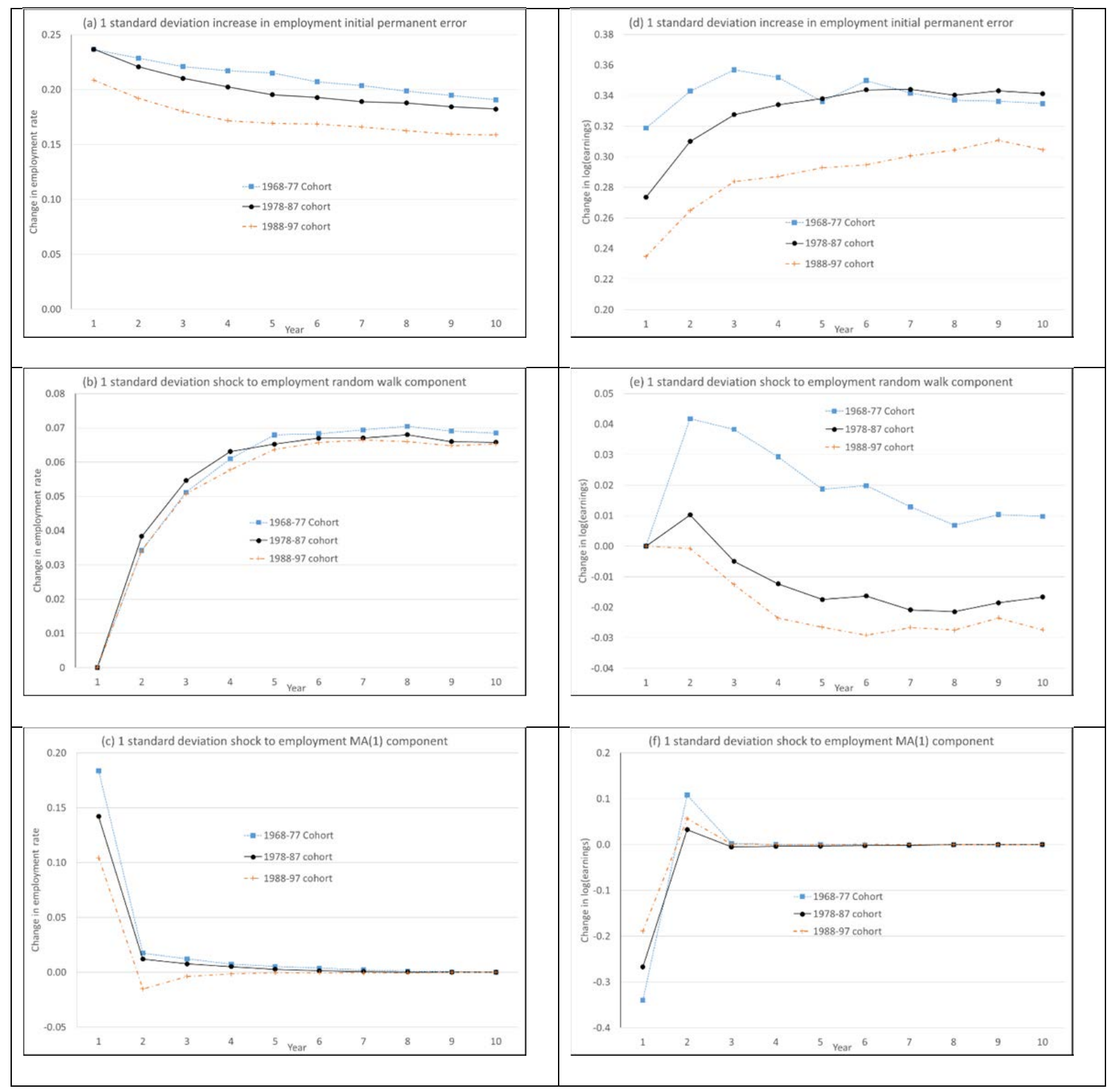


Appendix Figure 4: Dynamic responses of Employment and log(earnings) to earnings shocks

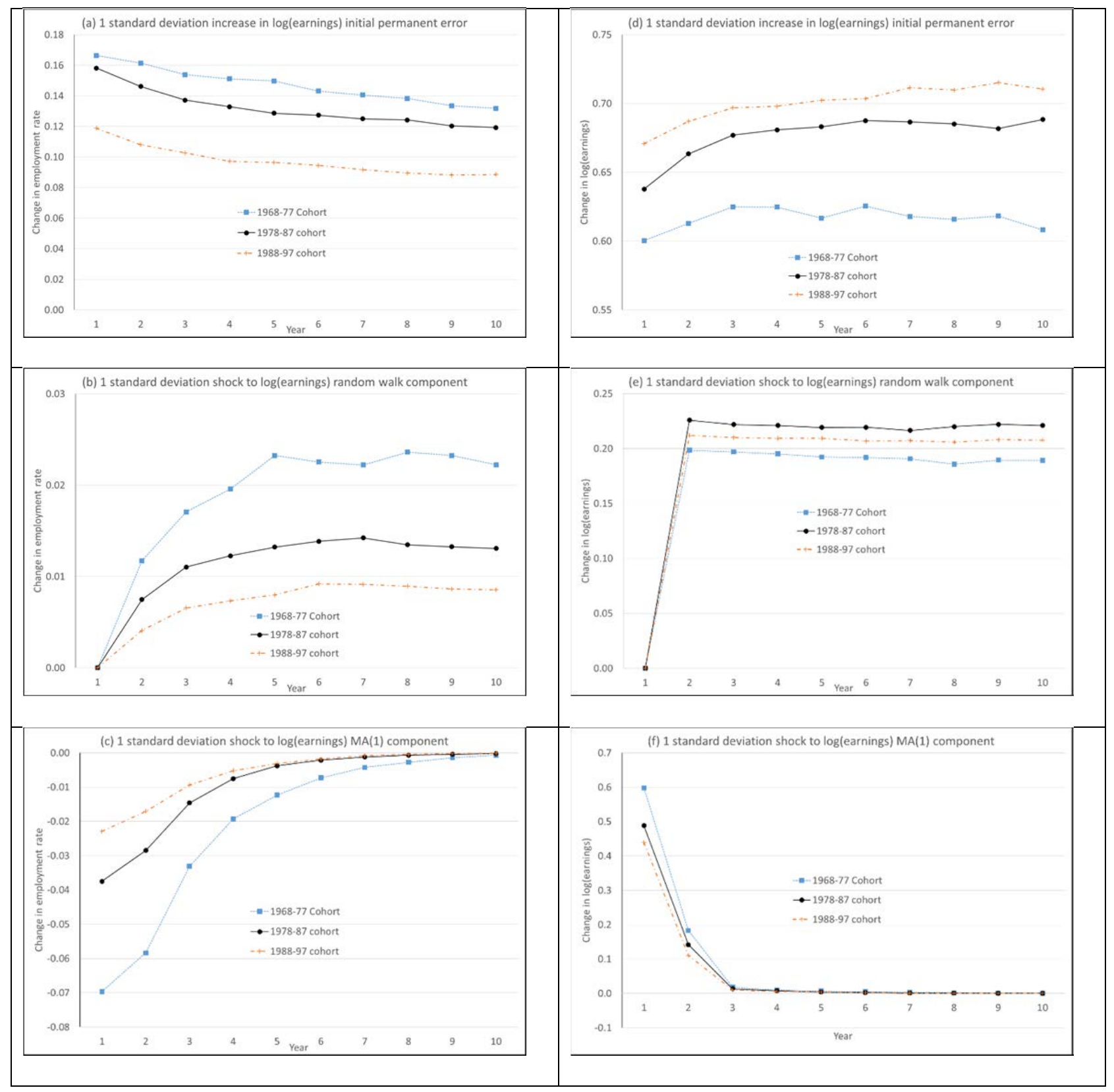


Appendix Table 1: Characteristics of Female Heads in Three 10-year Panels of PSID (Excluding SEO Subsample)

\begin{tabular}{|c|c|c|c|c|c|c|c|c|c|}
\hline & \multicolumn{3}{|c|}{$1968-77$} & \multicolumn{3}{|c|}{$1978-87$} & \multicolumn{3}{|c|}{$1988-97$} \\
\hline & All & Not Emp. & Employed & All & Not Emp. & Employed & All & Not Emp. & Employed \\
\hline$\overline{\text { Age }}$ & 41.7 & 41.8 & 41.7 & 39.5 & 40.2 & 39.3 & 39.7 & 40.6 & 39.6 \\
\hline Education & 12.0 & 11.7 & 12.2 & 13.1 & 12.5 & 13.3 & 13.5 & 12.9 & 13.6 \\
\hline Black & 0.09 & 0.06 & 0.11 & 0.08 & 0.09 & 0.08 & 0.07 & 0.08 & 0.07 \\
\hline Partner present & 0.84 & 0.94 & 0.77 & 0.81 & 0.90 & 0.78 & 0.81 & 0.90 & 0.79 \\
\hline Always with partner & 0.73 & 0.84 & 0.66 & 0.70 & 0.81 & 0.67 & 0.70 & 0.82 & 0.68 \\
\hline Never with partner & 0.08 & 0.03 & 0.11 & 0.11 & 0.06 & 0.12 & 0.10 & 0.06 & 0.11 \\
\hline Any kids present & 0.69 & 0.75 & 0.65 & 0.66 & 0.73 & 0.64 & 0.64 & 0.70 & 0.63 \\
\hline Number kids present & 1.66 & 1.95 & 1.47 & 1.32 & 1.56 & 1.23 & 1.28 & 1.55 & 1.21 \\
\hline Kid under 6 present & 0.22 & 0.32 & 0.16 & 0.26 & 0.36 & 0.22 & 0.25 & 0.37 & 0.23 \\
\hline Kid 6-17 present & 0.47 & 0.44 & 0.49 & 0.40 & 0.37 & 0.42 & 0.39 & 0.33 & 0.40 \\
\hline Ever have kids present & 0.84 & 0.88 & 0.82 & 0.83 & 0.85 & 0.82 & 0.79 & 0.84 & 0.78 \\
\hline Always have kids present & 0.51 & 0.58 & 0.46 & 0.46 & 0.54 & 0.43 & 0.45 & 0.51 & 0.43 \\
\hline \multicolumn{10}{|l|}{ Own employment outcomes: } \\
\hline Fraction years employed & 0.60 & 0.23 & 0.84 & 0.73 & 0.31 & 0.89 & 0.82 & 0.36 & 0.92 \\
\hline Always employed & 0.31 & 0.00 & 0.52 & 0.46 & 0.00 & 0.62 & 0.57 & 0.00 & 0.69 \\
\hline Never employed & 0.15 & 0.37 & 0.00 & 0.07 & 0.26 & 0.00 & 0.04 & 0.23 & 0.00 \\
\hline Earnings this year & 13,270 & 0 & 22,212 & 19,316 & 0 & 26,372 & 27,260 & 0 & 33,296 \\
\hline Mean earn's (including 0's) & 13,270 & 2,860 & 20,285 & 19,316 & 4,182 & 24,844 & 27,260 & 6,523 & 31,852 \\
\hline \multicolumn{10}{|c|}{ Partner employment outcomes (in years partner present): } \\
\hline Partner age & 44.8 & 44.8 & 44.8 & 42.2 & 43.4 & 41.7 & 42.1 & 43.4 & 41.8 \\
\hline Partner employed & 0.95 & 0.93 & 0.97 & 0.95 & 0.91 & 0.96 & 0.95 & 0.90 & 0.96 \\
\hline Partner hours this year & 2,314 & 2,379 & 2,261 & 2,245 & 2,286 & 2,228 & 2,284 & 2,358 & 2,266 \\
\hline Partner earnings this year & 61,324 & 64,406 & 58,837 & 64,089 & 68,385 & 62,346 & 69,289 & 77,885 & 67,210 \\
\hline Mean partner earnings & 59,813 & 63,282 & 57,260 & 62,637 & 66,381 & 61,182 & 67,056 & 75,002 & 65,197 \\
\hline Number person-year obs. & 11,170 & 4,497 & 6,673 & 14,290 & 3,823 & 10,467 & 16,880 & 3,060 & 13,820 \\
\hline
\end{tabular}

Notes: See note to Table 1. 
Appendix Table 2: Characteristics of Male Heads in Three 10-year Panels of PSID

\begin{tabular}{|c|c|c|c|c|c|c|c|c|c|}
\hline & \multicolumn{3}{|c|}{$1968-77$} & \multicolumn{3}{|c|}{$1978-87$} & \multicolumn{3}{|c|}{$1988-97$} \\
\hline & All & Not Emp. & Employed & All & Not Emp. & Employed & All & Not Emp. & Employed \\
\hline$\overline{\text { Age }}$ & 42.0 & 49.4 & 41.8 & 39.2 & 44.8 & 39.0 & 40.0 & 43.8 & 39.8 \\
\hline Education & 11.4 & 9.0 & 11.5 & 13.0 & 11.2 & 13.1 & 13.5 & 12.1 & 13.6 \\
\hline Black & 0.27 & 0.47 & 0.26 & 0.25 & 0.45 & 0.24 & 0.23 & 0.41 & 0.22 \\
\hline Partner present & 0.91 & 0.78 & 0.92 & 0.87 & 0.75 & 0.87 & 0.85 & 0.67 & 0.86 \\
\hline Always with partner & 0.81 & 0.67 & 0.82 & 0.74 & 0.63 & 0.74 & 0.74 & 0.55 & 0.75 \\
\hline Never with partner & 0.03 & 0.07 & 0.03 & 0.05 & 0.14 & 0.05 & 0.07 & 0.20 & 0.06 \\
\hline Any kids present & 0.76 & 0.62 & 0.76 & 0.67 & 0.51 & 0.68 & 0.65 & 0.46 & 0.66 \\
\hline Number kids present & 2.14 & 2.02 & 2.14 & 1.40 & 1.18 & 1.41 & 1.32 & 1.04 & 1.33 \\
\hline Kid under 6 present & 0.31 & 0.21 & 0.32 & 0.31 & 0.20 & 0.32 & 0.29 & 0.20 & 0.29 \\
\hline Kid 6-17 present & 0.44 & 0.41 & 0.45 & 0.36 & 0.31 & 0.36 & 0.36 & 0.27 & 0.36 \\
\hline Ever have kids present & 0.90 & 0.83 & 0.90 & 0.85 & 0.78 & 0.86 & 0.82 & 0.69 & 0.82 \\
\hline Always have kids present & 0.57 & 0.47 & 0.57 & 0.43 & 0.29 & 0.43 & 0.43 & 0.31 & 0.44 \\
\hline \multicolumn{10}{|l|}{ Own employment outcomes: } \\
\hline Fraction years employed & 0.96 & 0.39 & 0.99 & 0.95 & 0.44 & 0.98 & 0.95 & 0.50 & 0.97 \\
\hline Always employed & 0.89 & 0.00 & 0.92 & 0.85 & 0.00 & 0.90 & 0.82 & 0.00 & 0.86 \\
\hline Never employed & 0.01 & 0.25 & 0.00 & 0.01 & 0.20 & 0.00 & 0.01 & 0.13 & 0.00 \\
\hline Earnings this year & 52,699 & 0 & 54,688 & 55,871 & 0 & 58,522 & 60,251 & 0 & 63,452 \\
\hline Mean earn's (including 0's) & 52,699 & 13,621 & 54,174 & 55,871 & 16,226 & 57,752 & 60,251 & 20,854 & 62,344 \\
\hline \multicolumn{10}{|c|}{ Partner employment outcomes (in years partner present): } \\
\hline Partner age & 39.0 & 45.7 & 38.8 & 37.0 & 42.8 & 36.8 & 38.0 & 40.9 & 37.9 \\
\hline Partner employed & 0.53 & 0.42 & 0.53 & 0.71 & 0.54 & 0.72 & 0.80 & 0.70 & 0.81 \\
\hline Partner hours this year & 1,264 & 1,400 & 1,260 & 1,427 & 1,488 & 1,425 & 1,617 & 1,764 & 1,611 \\
\hline Partner earnings this year & 17,904 & 15,499 & 17,967 & 23,977 & 22,652 & 24,019 & 31,747 & 31,670 & 31,750 \\
\hline Mean partner earnings & 14,766 & 11,369 & 14,868 & 21,324 & 18,293 & 21,433 & 29,271 & 26,765 & 29,379 \\
\hline Number person-year obs. & 15,150 & 551 & 14,599 & 20,550 & 931 & 19,619 & 18,990 & 958 & 18,032 \\
\hline
\end{tabular}

Notes: See note to Table 1. 
Appendix Table 3: Decomposition of Earnings Inequality, Samples Excluding SEO

\begin{tabular}{|c|c|c|c|c|c|c|}
\hline & \multicolumn{3}{|c|}{ Female Heads: } & \multicolumn{3}{|c|}{ Male Heads: } \\
\hline & 1968-1977 & 1978-1987 & 1988-1997 & 1968-1977 & 1978-1987 & 1988-1997 \\
\hline Total $\mathrm{CV}^{2}$ of annual earnings & 1.60 & 1.10 & 0.88 & 0.27 & 0.35 & 0.47 \\
\hline $\begin{array}{l}\text { Within-person component } \\
\text { (share of total) }\end{array}$ & $\begin{array}{c}0.38 \\
(0.24)\end{array}$ & $\begin{array}{c}0.25 \\
(0.22)\end{array}$ & $\begin{array}{c}0.20 \\
(0.23)\end{array}$ & $\begin{array}{c}0.06 \\
(0.21)\end{array}$ & $\begin{array}{c}0.08 \\
(0.24)\end{array}$ & $\begin{array}{c}0.11 \\
(0.24)\end{array}$ \\
\hline Wtd. avg of $\mathrm{CV}_{\mathrm{i}}^{2}$ (approx. within) & 0.36 & 0.24 & 0.21 & 0.06 & 0.08 & 0.11 \\
\hline $\begin{array}{l}\text { Between-person component } \\
\text { (share of total) }\end{array}$ & $\begin{array}{c}1.31 \\
(0.82)\end{array}$ & $\begin{array}{c}0.89 \\
(0.81)\end{array}$ & $\begin{array}{c}0.68 \\
(0.77)\end{array}$ & $\begin{array}{c}0.22 \\
(0.81)\end{array}$ & $\begin{array}{c}0.27 \\
(0.77)\end{array}$ & $\begin{array}{c}0.36 \\
(0.76)\end{array}$ \\
\hline Cross-term & -0.09 & -0.04 & -0.02 & -0.01 & 0.00 & -0.01 \\
\hline \multicolumn{7}{|c|}{ Decomposition of within-person component: } \\
\hline $\begin{array}{l}\text { Extensive margin component } \\
\text { (share of total) }\end{array}$ & $\begin{array}{c}0.13 \\
(0.08)\end{array}$ & $\begin{array}{c}0.07 \\
(0.07)\end{array}$ & $\begin{array}{l}0.05 \\
(0.06)\end{array}$ & $\begin{array}{c}0.01 \\
(0.02)\end{array}$ & $\begin{array}{c}0.01 \\
(0.03)\end{array}$ & $\begin{array}{c}0.02 \\
(0.04)\end{array}$ \\
\hline $\begin{array}{l}\text { Intensive margin component } \\
\text { (share of total) }\end{array}$ & $\begin{array}{c}0.22 \\
(0.14)\end{array}$ & $\begin{array}{c}0.17 \\
(0.15)\end{array}$ & $\begin{array}{c}0.16 \\
(0.18)\end{array}$ & $\begin{array}{c}0.05 \\
(0.18)\end{array}$ & $\begin{array}{c}0.07 \\
(0.20)\end{array}$ & $\begin{array}{c}0.10 \\
(0.21)\end{array}$ \\
\hline \multicolumn{7}{|c|}{ Decomposition of between-person component: } \\
\hline $\begin{array}{l}\text { Extensive margin component } \\
\text { (share of total) }\end{array}$ & $\begin{array}{c}0.36 \\
(0.22)\end{array}$ & $\begin{array}{c}0.14 \\
(0.13)\end{array}$ & $\begin{array}{c}0.07 \\
(0.08)\end{array}$ & $\begin{array}{c}0.00 \\
(0.01)\end{array}$ & $\begin{array}{c}0.01 \\
(0.02)\end{array}$ & $\begin{array}{c}0.01 \\
(0.01)\end{array}$ \\
\hline $\begin{array}{l}\text { Intensive margin component } \\
\text { (share of total) }\end{array}$ & $\begin{array}{c}0.55 \\
(0.34)\end{array}$ & $\begin{array}{c}0.49 \\
(0.44)\end{array}$ & $\begin{array}{c}0.45 \\
(0.51)\end{array}$ & $\begin{array}{c}0.20 \\
(0.75)\end{array}$ & $\begin{array}{c}0.24 \\
(0.70)\end{array}$ & $\begin{array}{c}0.32 \\
(0.68)\end{array}$ \\
\hline $\begin{array}{l}\text { Cross-term } \\
\text { (share of total) }\end{array}$ & $\begin{array}{c}0.39 \\
(0.24)\end{array}$ & $\begin{array}{c}0.25 \\
(0.23)\end{array}$ & $\begin{array}{c}0.16 \\
(0.18)\end{array}$ & $\begin{array}{c}0.01 \\
(0.04)\end{array}$ & $\begin{array}{c}0.02 \\
(0.05)\end{array}$ & $\begin{array}{c}0.03 \\
(0.06)\end{array}$ \\
\hline Time variation & 0.02 & 0.01 & 0.00 & 0.00 & 0.00 & 0.00 \\
\hline
\end{tabular}

Notes: See text for details of decomposition. Samples exclude SEO subsample. 
Appendix Table 4: Estimated Parameters of Initial Conditions Employment Model

\begin{tabular}{|c|c|c|c|}
\hline & 1968-77 & $1978-87$ & $1988-97$ \\
\hline Partner Present & $\begin{array}{c}5.394 \\
(0.923)\end{array}$ & $\begin{array}{c}6.246 \\
(1.129)\end{array}$ & $\begin{array}{c}4.070 \\
(1.160)\end{array}$ \\
\hline Average (Partner Present) & $\begin{array}{l}-0.465 \\
(0.183)\end{array}$ & $\begin{array}{c}0.064 \\
(0.202)\end{array}$ & $\begin{array}{c}0.194 \\
(0.240)\end{array}$ \\
\hline Education & $\begin{array}{c}0.115 \\
(0.018)\end{array}$ & $\begin{array}{c}0.211 \\
(0.025)\end{array}$ & $\begin{array}{c}0.197 \\
(0.032)\end{array}$ \\
\hline Black & $\begin{array}{c}0.287 \\
(0.098)\end{array}$ & $\begin{array}{c}0.059 \\
(0.105)\end{array}$ & $\begin{array}{l}-0.183 \\
(0.132)\end{array}$ \\
\hline Age/10 & $\begin{array}{c}0.788 \\
(0.545)\end{array}$ & $\begin{array}{c}0.943 \\
(0.584)\end{array}$ & $\begin{array}{c}2.246 \\
(0.793)\end{array}$ \\
\hline Age-squared/100 & $\begin{array}{l}-0.125 \\
(0.073)\end{array}$ & $\begin{array}{l}-0.121 \\
(0.078)\end{array}$ & $\begin{array}{l}-0.315 \\
(0.108)\end{array}$ \\
\hline No. Children Present & $\begin{array}{c}0.056 \\
(0.056)\end{array}$ & $\begin{array}{l}-0.095 \\
(0.062)\end{array}$ & $\begin{array}{l}-0.016 \\
(0.098)\end{array}$ \\
\hline Average (No. Children Present) & $\begin{array}{l}-0.271 \\
(0.073)\end{array}$ & $\begin{array}{l}-0.121 \\
(0.090)\end{array}$ & $\begin{array}{l}-0.565 \\
(0.126)\end{array}$ \\
\hline Child $<5$ Present & $\begin{array}{l}-0.684 \\
(0.202)\end{array}$ & $\begin{array}{l}-0.793 \\
(0.186)\end{array}$ & $\begin{array}{l}-0.475 \\
(0.235)\end{array}$ \\
\hline Average 1 (Child $<5$ Present) & $\begin{array}{c}0.223 \\
(0.302)\end{array}$ & $\begin{array}{c}0.306 \\
(0.311)\end{array}$ & $\begin{array}{c}0.779 \\
(0.395)\end{array}$ \\
\hline Child 6-17 Present & $\begin{array}{l}-0.315 \\
(0.181)\end{array}$ & $\begin{array}{l}-0.203 \\
(0.166)\end{array}$ & $\begin{array}{l}-0.023 \\
(0.222)\end{array}$ \\
\hline Average( Child 6-17 Present) & $\begin{array}{l}-0.191 \\
(0.221)\end{array}$ & $\begin{array}{l}-0.087 \\
(0.234)\end{array}$ & $\begin{array}{c}0.287 \\
(0.298)\end{array}$ \\
\hline $\begin{array}{l}\text { Partner Never Employed (in years } \\
\text { present) }\end{array}$ & $\begin{array}{l}-5.622 \\
(0.974)\end{array}$ & $\begin{array}{l}-7.600 \\
(1.216)\end{array}$ & $\begin{array}{l}-5.008 \\
(1.255)\end{array}$ \\
\hline Partner Currently Employed & $\begin{array}{c}0.223 \\
(0.375)\end{array}$ & $\begin{array}{c}0.261 \\
(0.378)\end{array}$ & $\begin{array}{c}0.508 \\
(0.359)\end{array}$ \\
\hline Average( Partner Currently Employed) & $\begin{array}{c}0.756 \\
(0.403)\end{array}$ & $\begin{array}{c}0.763 \\
(0.367)\end{array}$ & $\begin{array}{c}0.907 \\
(0.472)\end{array}$ \\
\hline Partner's Mean(log earnings) & $\begin{array}{l}-0.625 \\
(0.088)\end{array}$ & $\begin{array}{l}-0.719 \\
(0.112)\end{array}$ & $\begin{array}{l}-0.569 \\
(0.118)\end{array}$ \\
\hline $\begin{array}{l}\text { Deviation: Partner log earnings } \\
\text { from Mean(log earnings) }\end{array}$ & $\begin{array}{l}-0.226 \\
(0.155)\end{array}$ & $\begin{array}{l}-0.513 \\
(0.143)\end{array}$ & $\begin{array}{l}-0.191 \\
(0.167)\end{array}$ \\
\hline Intercept & $\begin{array}{l}-0.897 \\
(1.005)\end{array}$ & $\begin{array}{l}-2.496 \\
(1.075)\end{array}$ & $\begin{array}{l}-3.699 \\
(1.379)\end{array}$ \\
\hline $\begin{array}{l}\text { Initial Condition Permanent Component } \\
\text { Loading Factor }\end{array}$ & $\begin{array}{c}2.405 \\
(0.263)\end{array}$ & $\begin{array}{l}2.445 \\
(0.277)\end{array}$ & $\begin{array}{c}2.656 \\
(0.347)\end{array}$ \\
\hline
\end{tabular}

Note: see note to Table 3. 